\title{
Secured and Unsecured Interbank Markets: Monetary Policy, Substitution and the Cost of Collateral
}

\author{
Thibaut Piquard ${ }^{1}$ and Dilyara Salakhova ${ }^{2}$
}

\author{
September 2019, WP \#730
}

\begin{abstract}
We study the substitution between secured and unsecured interbank markets. Banks are competitive and subject to reserve requirements in a corridor rate system with deposit and lending facilities. Banks face counterparty risk in the unsecured market and incur an opportunity cost to pledge collateral. The model provides insights on interest rates, trading volumes and substitution between the two markets. Using transaction data on the Euro money market, we provide new empirical findings that the model accounts for: (i) borrowing banks are active on both markets even when their collateral constraint is not binding, (ii) secured interest rates may fall below the deposit facility rate. We derive and empirically test predictions on how "conventional" and "unconventional" monetary policies impact interbank markets, depending on whether marketable collateral is purchased or not.
\end{abstract}

Keywords: Monetary Policy, Interbank Markets, Secured and Unsecured Funding.

JEL classification: E42; E52 ; E58 ; G21

\footnotetext{
${ }^{1}$ Macroprudential policy division Banque de France, and Paris School of Economics, thibaut.piquard@,banque-france.fr;

${ }^{2}$ Macroprudential policy division Banque de France, dilyara.salakhova@banque-france.fr;

We thank Morten Bech for the discussion of the paper and very insightful comments. We are also grateful to Hugues Dastarac, Jean-Pierre Danthine, Gabrielle Demange, Jean-David Sigaux, Miklos Vari and participants of seminars at the Banque de France and conference on Monetary Policy. Dilyara Salakhova is a member of one of the user groups with access to TARGET2 data in accordance with Article 1(2) of Decision ECB/2010/9 of 29 July 2010 on access to and use of certain TARGET2 data. The Banque de France and the PSSC have checked the paper against the rules for guaranteeing the confidentiality of transaction-level data imposed by the PSSC pursuant to Article 1(4) of the above-mentioned issue. The views expressed in the paper are solely those of the author(s) and do not necessarily represent the views of the Eurosystem or the Banque de France. All the errors are ours alone.
}

Working Papers reflect the opinions of the authors and do not necessarily express the views of the Banque de France. This document is available on publications.banque-france.fr/en 


\section{NON-TECHNICAL SUMMARY}

Secured and unsecured money markets are prime short-term funding markets for banks. They play a key role in the transmission of monetary policy, and while the interbank unsecured interest rate is the actual monetary policy target of most central banks around the world, the repo market has only recently attracted attention of policy makers when repo rates went below the deposit facility rate. However, there is still lack in understanding how banks decide in which market to trade, and how the two markets co-exist and react to monetary policy.

In this paper, we study the joint behaviour of banks in the unsecured and secured markets.

Some questions that we aim to address in this paper include; do banks borrow on the unsecured market because of collateral shortage? Why and when can repo rates go outside of the monetary policy corridor? What is the role of unconventional monetary policy and counterparty risk in the allocation between the two markets?

We start by documenting new empirical facts regarding these markets. We use transaction level data from the payment system TARGET2 to retrieve the unsecured interbank loans and a unique dataset from the Eurex GC Pooling market, an interbank market operated by Eurex. We first show that banks may borrow on both markets, even when their collateral constraint is not binding. This new finding sheds light to former theoretical contributions. It reveals that banks funding policy does not follow a pecking order; they do not strictly prefer a type of funding to the other. Instead, unsecured and secured borrowings are imperfect substitutes for banks. Second, we document that both unsecured and secured volumes drop when excess reserves rise, confirming evidence from the literature. Third, we show that increasing excess reserves drives the unsecured rate to the ECB deposit facility rate, but the rate in the secured market may fall below the deposit facility rate when excess reserves are high. This fact is surprising because neither imperfect competition with non-banks, nor repo specialness (the need to hold a specific security) is present in our data. These two usually explain why the repo rate may fall below the deposit facility rate. Indeed, in our data, the participants are only European banks, and lenders do not receive special securities but a claim on a basket of collateral managed by Eurex.

Then, we build a model that is able to account for such stylized facts. Like the benchmark model from Poole (1968), banks are subject to shocks on their reserve holdings in a corridor rates system with reserve requirements. However, banks can lend or borrow simultaneously in the two markets: the unsecured and the secured one, in exchange for collateral. We introduce two financial frictions: lending banks face counterparty risk in the unsecured market, and all banks incur an opportunity cost of collateral, that is, they derive some additional utility from holding bonds that unpledged in the secured market.

These financial frictions help us to explain the aforementioned stylized facts. Banks do not trade in the unsecured market if counterparty risk is too high; otherwise, they trade in both the unsecured and secured markets. Borrowers pledge all their collateral in the secured market if the marginal gain from holding reserves exceeds the opportunity cost of collateral, namely if counterparty risk or reserve requirements are high. If the counterparty risk is low enough, they do not pledge all their collateral and borrow on both markets. Because of the opportunity cost of collateral, lenders value holding additional collateral. Therefore, rates in the secured markets are not bounded below by the deposit facility rate.

Finally, we show how "conventional" and "unconventional" monetary policies differently affect interbank markets. While the two monetary policies similarly affect aggregate volumes and the unsecured rate, they change the substitution and spread between the two markets because they have opposite effects on the opportunity cost of collateral. Empirical tests confirm such predictions: the VLTRO and APP similarly affect unsecured interest rates while the secured rates relatively decrease when the central bank purchases marketable collateral. 


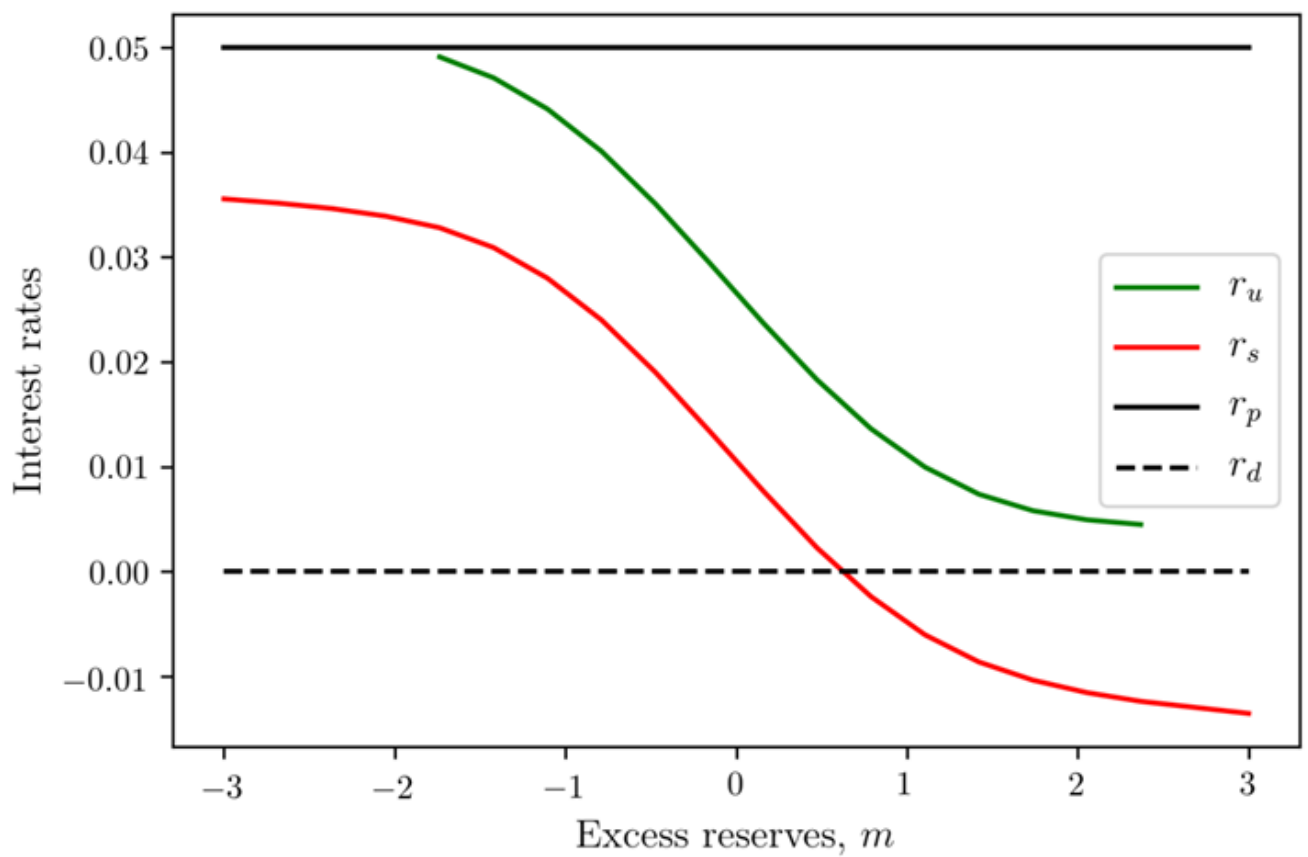

The central bank corridor lies between $\boldsymbol{r}_{\boldsymbol{d}}$ (deposit facility) and $\boldsymbol{r}_{\boldsymbol{p}}$ (lending facility). $\boldsymbol{r}_{\boldsymbol{u}}$ stands for the unsecured rate while $\boldsymbol{r}_{\boldsymbol{s}}$ stands for the secured rate. The figure presents how interest rates move with excess reserves $m$. The figure does not display the unsecured rate if banks exchange no volumes on the unsecured market. Source: Piquard Salakhova (2019).

\section{Marchés collatéralisés et non-collatéralisés : politique monétaire, substitution et coût du collatéral}

\section{RÉSUMÉ}

Nous étudions la substitution entre les marchés interbancaires collatéralisés et noncollatéralisés. Des banques compétitives sont soumises à un ratio de réserve dans un système de refinancement ayant une facilité de dépôt et une autre de refinancement. Les banques font face à du risque de contrepartie dans le marché non-collatéralisé et sont sujettes à un coût d'opportunité du collatéral. Notre model décrit le comportement des taux d'intérêts, volumes échangés et de la substitution entre les deux marchés. Nous utilisons des données granulaires des marchés interbancaires pour établir de nouveaux faits stylisés expliqués par le modèle : (i) les banques empruntent sur les deux marchés, même quand leur contrainte de collatéral n'est pas saturée, (ii) les taux du marché collatéralisé peuvent descendre sous le taux de la facilité de dépôt. Nous établissons et testons des prévisions du modèle concernant l'impact différencié des politiques monétaires « conventionnelles » et « non-conventionnelles».

Mots-clés : Politique Monétaire, Marchés Interbancaires, Refinancement Collatéralisé et NonCollatéralisé

Les Documents de travail reflètent les idées personnelles de leurs auteurs et n'expriment pas nécessairement la position de la Banque de France. Ils sont disponibles sur publications.banque-france.fr 


\section{Introduction}

Secured and unsecured money markets are prime short-term funding markets for banks. They play a key role in the transmission of monetary policy. So far, the interbank unsecured interest rate has been the actual monetary policy target of most central banks around the world. ${ }^{1}$ The repo market has relatively recently attracted the attention of policy makers when the relative importance of the two markets swapped, and rates of European collateralized loans fell below the ECB's deposit facility rate. However, there is still lack in understanding how banks decide to substitute funding in both markets, and how the two markets co-exist and react to monetary policy. Some questions that we aim to address in this paper include: do banks borrow on the unsecured market because of collateral shortage? Why and when do repo rates go outside of the monetary policy corridor? What is the role of monetary policy and counterparty risk in the substitution between the two markets?

In this paper, we establish new facts on the substitution between secured and unsecured markets using both aggregate and individual data on banks' overnight lending/borrowing activity in the European interbank general collateral (GC) repo and unsecured money markets. To explain the mechanisms behind the observed facts, we build a model that features decisions of individual banks in trading on both markets given central bank interest rates and reserve requirements. We start with the classical model of monetary policy implementation by Poole (1968) and add the secured interbank market and two frictions: counterparty risk in the unsecured market and an opportunity cost to pledge collateral in the secured market. Some evidence suggests that such opportunity cost indeed exists. ${ }^{2}$ Furthermore, using the insights from the model we show which mechanisms explain the established facts. In particular, we show that because of the opportunity cost of collateral, interest rates in the secured market can go below the deposit facility rate (DFR) in the market where only banks are present and repo trades are done against general collateral (not "special" securities). The opportunity cost of collateral itself may stem from imperfect competition or "special" repo trades as suggested in the literature (e.g., Arrata, Nguyen, Rahmouni-Rousseau, and Vari (2017), Huh and Infante (2017), Bech and Klee (2011)).

We establish the empirical evidence using two data sources: a database on all unsecured loans made through the large value payment system TARGET2 $2^{3}$ and a database on repo transactions between individual participants and Eurex in the GC-pooling market. ${ }^{4}$ These data are representative of European interbank repo transactions that are cash driven since the collateral part is not a specific security but a large pool of pre-specified securities.

\footnotetext{
${ }^{1}$ See, e.g., Amstad and Martin (2011)

${ }^{2}$ In particular, the introduction of securities lending by the ECB in December 2016 and, especially, the possibility to pledge cash as collateral to borrow securities at the ECB significantly eased tensions on the repo markets. For more details, see Asset purchases, financial regulation and repo market activity, speech by Benoit Coeuré at the ERCC General Meeting on "The repo market: market conditions and operational challenges", Brussels, 14 November 2017; Ructions in the repo market - monetary easing or regulatory squeezing?, speech by Yves Mersch, member of the Executive Board of the ECB, at the GFF summit, Luxembourg, 26 January 2017.

${ }^{3}$ See Arciero, Heijmans, Heuver, Massarenti, Picillo, and Vacirca (2016) for details on the implementation and validation of the algorithm to filter out unsecured interbank loans in a large-value payment system TARGET2.

${ }^{4}$ See Mancini, Ranaldo, and Wrampelmeyer (2016) for more details on this market.
} 
The first empirical finding shows that banks may be active on both markets even when their collateral constraint is not binding. We evaluate banks' available collateral by observing daily balances of unencumbered collateral pledged at the Eurosystem and conclude that substitution between repo and unsecured markets is not the result of collateral shortage on the borrower's side. This is a new finding in the literature that sheds light on the substitution between unsecured and secured funding at the bank level. Indeed, most theoretical papers focus on corner solutions: banks first borrow on the secured market and then go on the unsecured market when they are short of collateral (see, e.g., Freixas and Holthausen (2005), Heider and Hoerova (2009), Gale and Yorulmazer (2013) and Ranaldo, Rupprecht, and Wrampelmeyer (2016)). The second finding focuses on the evolution of overnight trading volumes and confirms others' results that volumes on both markets drop when excess reserves rise.

The third finding discusses the impact of monetary policy on the interest rates of the two markets. Increasing excess reserves decrease interest rates on both markets. It drives the interest rate on the overnight unsecured market towards the deposit facility rate, while interest rates on the secured market may fall below the deposit facility rate (DFR). The latter observation is indeed puzzling and attracted a lot of attention from policy makers. ${ }^{5}$ The reason is that the deposit facility rate set by the European central bank (ECB) has always been considered an effective floor for interest rates on European interbank money markets. Other studies have tried to explain this observation but in different market setups, for example for "special" repo trades or in presence of non-banks in the market. In our case, the specificity of the Eurex GC market institutional set-up allows us to rule out imperfect competition (Bech and Klee (2011) for the U.S. fed funds market) as a reason explaining the negative spread between repo rate and DFR. All participants in Eurex GC-pooling platform are banks with equal access to the ECB standing facilities and trading anonymously on an open order book. These characteristics prevent stigma and signalling effects. ${ }^{6}$ And the Eurex market is general collateral repo transactions meaning that banks trade against a quite large pool of collateral against specific securities of "special" repo market.

While the implementation of monetary policy by the ECB and the institutional set-up of Eurex are specific to the European market, the co-existence of secured and unsecured markets, their mutual dynamics and reaction to traditional and unconventional monetary policies are common to many countries. Both the Bank of England and Federal Reserve documented various dynamics between the two markets since the 2008-2009 financial crisis and particularly since the beginning of the unconventional monetary policy (see, e.g., Jackson and Sim (2013), Bech, Klee, and Stebunovs (2012)). The Federal Reserve implemented new tools to steer better the fed funds rate (Martin, McAndrews, Palida, and Skeie (2013)) and studied a possibility of targeting an interbank repo rate as its monetary policy target (Klee and Stebunovs (2013)). To a different degree, both markets experienced a significant decrease in interest rates as well as fall in traded volumes with the increase

\footnotetext{
${ }^{5}$ See, e.g., Asset purchases, financial regulation and repo market activity, speech by Benoit Coeuré at the ERCC General Meeting on "The repo market: market conditions and operational challenges", Brussels, 14 November 2017; Ructions in the repo market - monetary easing or regulatory squeezing?, speech by Yves Mersch, member of the Executive Board of the ECB, at the GFF summit, Luxembourg, 26 January 2017.

${ }^{6}$ Mancini, Ranaldo, and Wrampelmeyer (2016) suggest it enhanced the resilience of the GC Pooling market during the Lehman and sovereign crisis.
} 
in excess reserves.

After establishing these facts, we build a model with both secured and unsecured interbank funding in a corridor rates system with reserve requirements and competitive markets. Banks are subject to shocks on their reserve holdings as in Poole (1968) seminal model. Early shocks on reserves feature the only heterogeneity in this context. We add a repo interbank market. Borrowing banks must pledge collateral to borrow in the secured market, holding a positive quantity of unpledged bonds (global box constraint). We introduce two financial frictions to explain the aforementioned stylized facts: (i) lending banks face counterparty risk in the unsecured market, and (ii) banks incur an opportunity cost to pledge collateral, when the extent of counterparty risk and the opportunity cost to pledge collateral along with the overall gain from sharing reserves allow for interior solutions. ${ }^{7}$ Namely, banks do not trade in the unsecured market if the counterparty risk is too high, and trade in both markets if the latter is low enough. Borrowers pledge all their collateral if the gains from trade and the counterparty risk are high enough, in which case it is profitable to trade but the counterparty risk prevent them to trade in the unsecured market. If the counterparty risk is low enough, both markets are active and borrowers do not use their total collateral (stylized fact 1). Increasing excess reserves decreases the total gain from trading in money markets. Therefore, volumes drop in both markets (stylized fact 2). While the interest rate in the unsecured market is bounded below by the deposit facility rate at the central bank, the rate in the secured market might drop below this threshold (stylized fact 3).

Finally, we show how "conventional" and "unconventional" monetary policies differently affect interbank markets. "Conventional" monetary policy alters only the liquidity supply thus affecting solely the gain from sharing reserves. In contrast, "unconventional" monetary policy changes both the liquidity supply and the marketable collateral base. Therefore, it also tilts the opportunity cost of collateral and affects the dynamics of rates and the substitution between the two markets. We show the two policies have similar effects on the unsecured rate and the aggregate volume, as these are only driven by the change in the liquidity. In contrast, the change in the substitution between the secured and unsecured market is driven by the marginal opportunity cost to pledge collateral. Moreover, we empirically test these predictions using aggregate daily data on secured and unsecured interest rates from 2008 to 2017. The monetary policy altering solely excess reserves can be associated with VLTRO while the other one corresponds to the Eurosystem's Asset Purchasing Programme. We demonstrate empirically that in line with our model both monetary policy regimes affect unsecured interest rate in the same way; the secured interest rate relatively decreases when the central bank increases liquidity in the market by purchasing (reducing) marketable collateral; the spread between the secured and unsecured rates increases under monetary policy that purchases marketable collateral. However, due to the operational set-up, we are not able to confirm the hypothesis that the monetary policy solely increasing the liquidity supply decreases the spread because any monetary policy affects both liquidity supply and collateral base: even for conventional monetary policy operations (MRO, LTRO) the central bank provides loans against collateral thus altering the availability of the latter.

\footnotetext{
${ }^{7}$ The gain from sharing reserves depends on the monetary policy parameters, such as the spread between the lending and deposit facilities, the amount of excess reserves.
} 
In line with ongoing debates on monetary policy implementation, two policy implications might be derived from our model. First, interbank markets are not perfect substitutes. Mechanisms underlying the interplay between unsecured and secured markets depend on the counterparty risk and the opportunity cost to pledge collateral. Therefore, should central banks target secured interest rates, they must account for the fact that the substitution and the interest rates depend on parameters outside the banking system, namely the global demand for collateral. This demand for collateral might be particularly difficult to estimate. Second, the model predicts that unconventional monetary policy such as the asset purchase program tilts the dynamics between the two markets and speeds up the fall of secured interest rates. Predicting how the substitution changes requires the knowledge of the marginal opportunity cost of collateral.

Our work is related to three strands of the literature. First, our paper contributes to the literature dealing with the substitution between secured and unsecured interbank money markets. Most papers taking into account the substitution between secured and unsecured funding derive corner solutions: banks borrow on both secured and unsecured markets only if they are short of collateral, see, e.g., Freixas and Holthausen (2005), Heider and Hoerova (2009), Gale and Yorulmazer (2013) and Ranaldo, Rupprecht, and Wrampelmeyer (2016). Secured funding helps lenders to avoid counterparty risk (exacerbated by asymmetry of information). In equilibrium, lenders are indifferent between both markets while borrowers strictly prefer to borrow on the secured market since it is cheaper. In our model, instead of asymmetry of information we introduce counterparty risk and an opportunity cost to pledge collateral as the two frictions allowing for interior solutions with borrowers not being short of collateral. Regards the empirical evidence, Mancini, Ranaldo, and Wrampelmeyer (2016) study the setting of the GC Pooling market and its effect on the market resilience while di Filippo, Ranaldo, and Wrampelmeyer (2016) investigate the substitution effect between the two markets: the unsecured market and the Eurex GC Pooling repo market.

Second, we complement the literature on monetary policy implementation in money markets adding the secured market into the game. This literature provides a framework to analyse how central banks steer unsecured market interest rates when they set monetary policy interest rates and reserve requirements. The seminal work by Poole (1968) motivates interbank trades by heterogeneous reserve holdings. Banks are subject to reserve requirements in a corridor rate system and trade reserves to insure against a late settlement shock arising when markets are closed. Because there are no trading frictions, banks perfectly share excess reserves and traded volumes do not move with excess reserves. Whitesell (2006) compares pure reserves regime to interest rate corridors. Afonso and Lagos (2015) introduce search models in the interbank market to account for intraday volatility and rates. Bech and Monnet (2016) add a trading friction to prevent perfect sharing of shocks. In a search model, banks are subject to a settlement shock if they choose to trade. As the benefit from trading reduces with the surge in excess reserves, it might be not profitable for some banks to trade when excess reserves are high. Therefore, volumes in the interbank market drop with excess reserves. Hauck and Neyer (2014) use quadratic transaction costs to prevent perfect sharing of reserves. In this case, banks do not exit the market but reduce volumes exchanged. In addition, Vari (2016) discusses monetary policy implementation when markets are segmented: some banks may choose to hold large amounts of excess reserves because they expect that they could loose 
access to the interbank market.

Third, our work is also related to the impact of monetary policy on secured interest rates, especially since some of these rates have gone below the deposit facility rate. Arrata, Nguyen, RahmouniRousseau, and Vari (2017) empirically investigate the channels through which asset purchases by the central bank affect secured interest rates. Using repo trade data, they document the extent of aggregate effects (excess liquidity) and bond specific effects on repo interest rates. For interest rates to go below the deposit facility rate, we need an opportunity cost to hold collateral. It stems from imperfect competition in the bond market (Huh and Infante (2017)) or in money markets (e.g. Bech and Klee (2011)). Repo "specialness" (Duffie (1996)) also supports this opportunity cost.

The remaining of the paper is organized as follows. We first establish some empirical facts from aggregate and individual transactions data in section 2 . We present the model and discuss the equilibrium in section 3. Finally, we present the results in section 4 and test the predictions of the model. Section 5 concludes.

\section{Empirical findings on the secured and unsecured markets}

In this section, we discuss new facts on interbank GC-Pooling secured and unsecured markets. We are interested in banks' decisions to trade in these two markets in relation to their funding needs, trading reserves. Therefore we focus on Euro cash-driven interbank transactions in the overnight unsecured market, as observed in the TARGET2 payment system, and on overnight trades in the Eurex GC-Pooling platform. We provide more details on the institutional framework of interbank markets in appendix 6.1.

We first address the substitution between GC Pooling and unsecured markets. di Filippo, Ranaldo, and Wrampelmeyer (2016) are the first to document empirically substitution between these two markets. In the theoretical literature, Freixas and Holthausen (2005) and Gale and Yorulmazer (2013) among others suggest that banks strictly prefer repo borrowing, and borrow on the unsecured market solely when they are collateral constrained to borrow on the repo market. To establish our first stylized fact, we do two things: first, we get a proxy of banks' available collateral by using information on Target 2 credit lines, namely, amount of collateral pledged by each bank at the Eurosystem for monetary policy and other operations. This collateral is unencumbered and can be withdrawn at any moment for funding in the repo market. The Eurosystem and Eurex GC Pooling accept marketable securities of a similar quality. We control for non-marketable securities pledged at the Eurosystem: banks in our sample are essentially from a certain country, and according to the statistics of the national central bank of this country non-marketable securities represent less than $20 \%$ of the total pledged collateral. Since banks in our sample are very heterogenous in terms of total assets, we take a ratio of the collateral amount over bank total assets in order to have comparable values across the sample.

Second, we compute a substitution rate, namely, the proportion of daily amounts borrowed on 
the unsecured market by each bank over total borrowing on both markets. Then for a 2014-2016 sample period of daily bank-level data, we split substitution rates in 5 equal brackets and plot the distributions of daily available collateral (over banks' total assets) for each bracket (see Figure 1). ${ }^{8}$ We observe a lot of heterogeneity in both available collateral and the proportion of unsecured borrowing, but distributions of available collateral for each bracket of unsecured borrowing are very similar. If the hypothesis of strict preference of repo borrowing over unsecured borrowing were true, we should see no unsecured borrowing whenever pledged collateral is positive.

Stylized fact 1: Banks may borrow and lend on both markets simultaneously even when their collateral constraint is not binding.

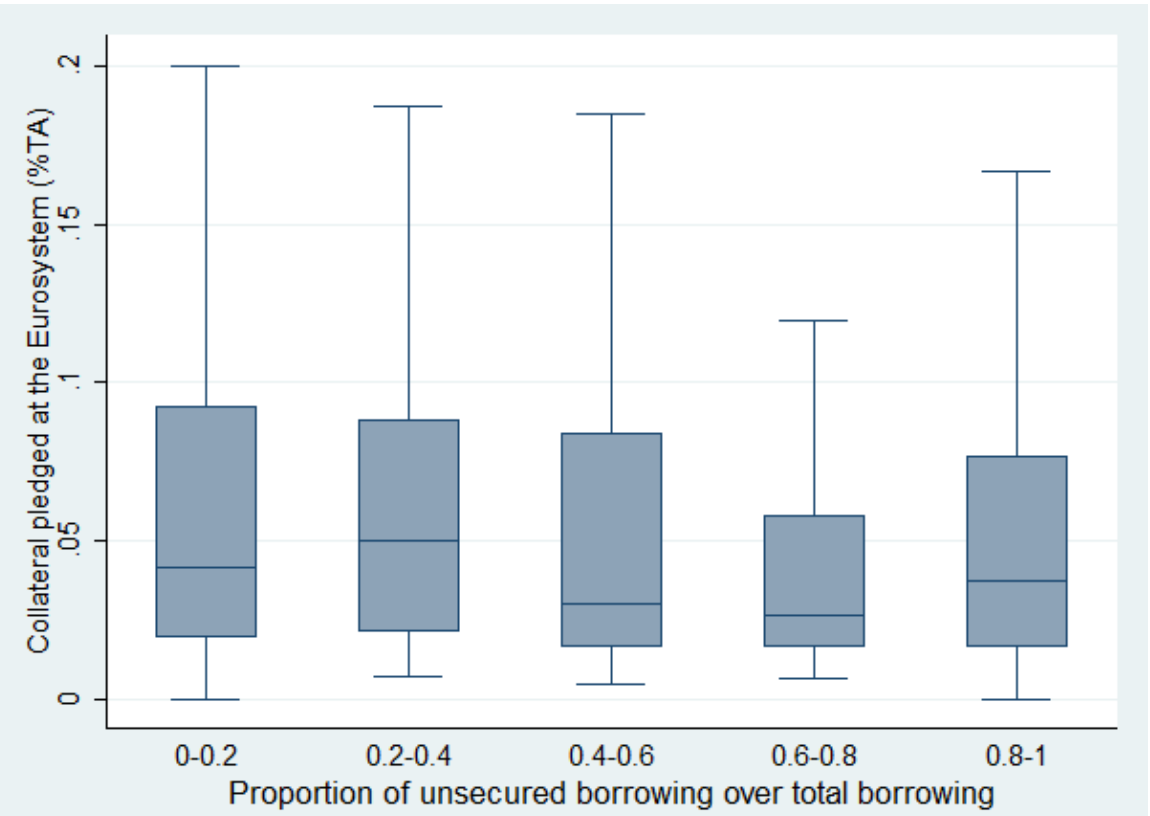

Figure 1: Fraction of unsecured borrowing in total borrowing vs. the amount of collateral pledged at the ECB (as \% of banks' total assets).

We use daily bank-level data over 2014-2016 for our sample of banks. Collateral pledged at the Eurosystem is unencumbered and can be used for market operations at any moment if the quality allows. Marketable securities that can be used for market operations constitute about $20 \%$ of total pledged collateral for the banks in the sample.

Figure 2 shows a non-linear dynamics between volumes on unsecured and repo markets. We can see that from 2008 to 2012, volumes in the two markets had largely opposite trends with the unsecured market losing its importance and the secured market gaining a higher share. However, with the rise in excess reserves both markets seem to synchronise and suffer significant drops in exchanged volumes. Interestingly, the repo market revives more quickly: end-2014, when excess reserves fell to lower levels, the repo market reached volumes similar to 2011, before ECB liquidity provisions through 3-year LTRO programs. As for the unsecured market, since 2008 it largely follows a decreasing trend. Since banks use these markets for funding reasons, the effect of excess reserves on the money markets underlines that banks have less motives to go to the interbank market when they have enough liquidity to satisfy their reserves requirements. These tendencies are similar for both the aggregate market volumes (Figure 2) and for our sample of banks (Figure 3).

\footnotetext{
${ }^{8}$ The reliable data on credit lines in the TRAGET2 are available only for 2014-2016 period.
} 
Stylized fact 2: Volumes in interbank markets drop when excess reserves increase.

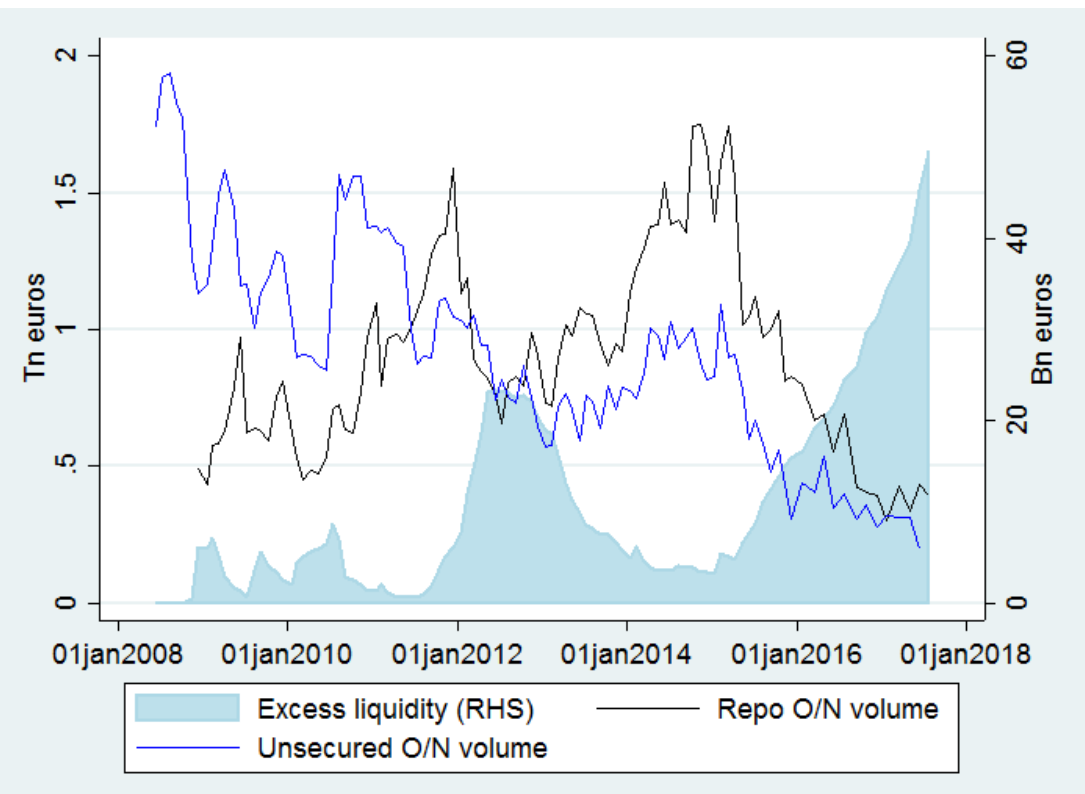

Figure 2: Aggregate volumes in interbank unsecured and repo markets.

Unsecured $\mathrm{O} / \mathrm{N}$ volume is equal to EONIA volume. Repo $\mathrm{O} / \mathrm{N}$ volume includes trades on the GC Pooling market both for ECB and extended baskets. The daily data are averaged over reserves maintenance periods.

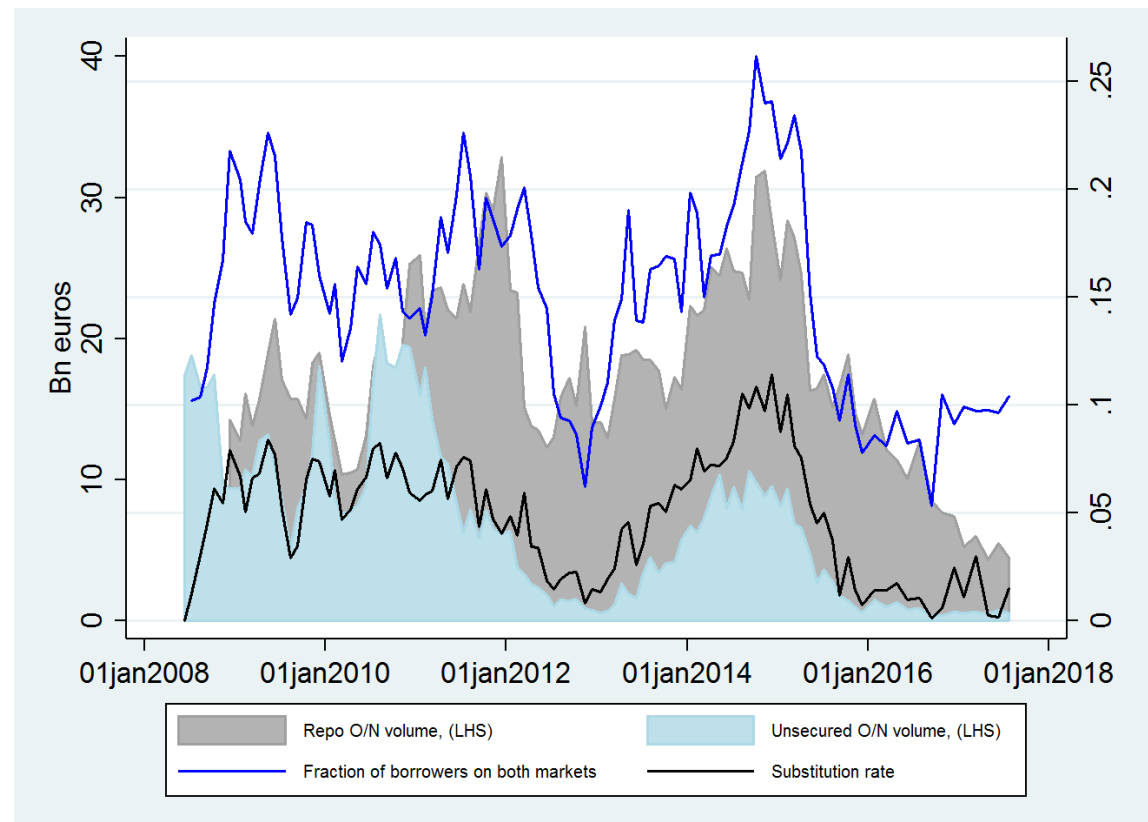

Figure 3: Fraction of borrowing on the unsecured market over time.

Volumes for both markets are computed for our sample of banks. Fraction of borrowers on both markets over total number of borrowers. The substitution rate is computed as a fraction for borrowing on the unsecured market over total borrowing only for banks that borrow on the two markets in the same day. The daily data are averaged over reserves maintenance periods.

The effect of excess reserves on the unsecured interbank market rates has been largely discussed in the literature (see, e.g., Bech and Monnet (2016), Vari (2016)), however rates on the secured markets have attracted little attention until the Eurosystem's asset purchases programme (APP). 
Figure 4 shows that both unsecured and secured market rates are sensitive to the level of excess reserves. Moreover, GC interest rates have gone below the deposit facility rate which was considered an effective floor of all interbank rates.

Stylized fact 3: An increase in excess reserves decreases the interest rates in both markets. It drives the interest rates on the unsecured market towards the deposit facility rate, while interest rates on the secured market may fall below the deposit facility rate.

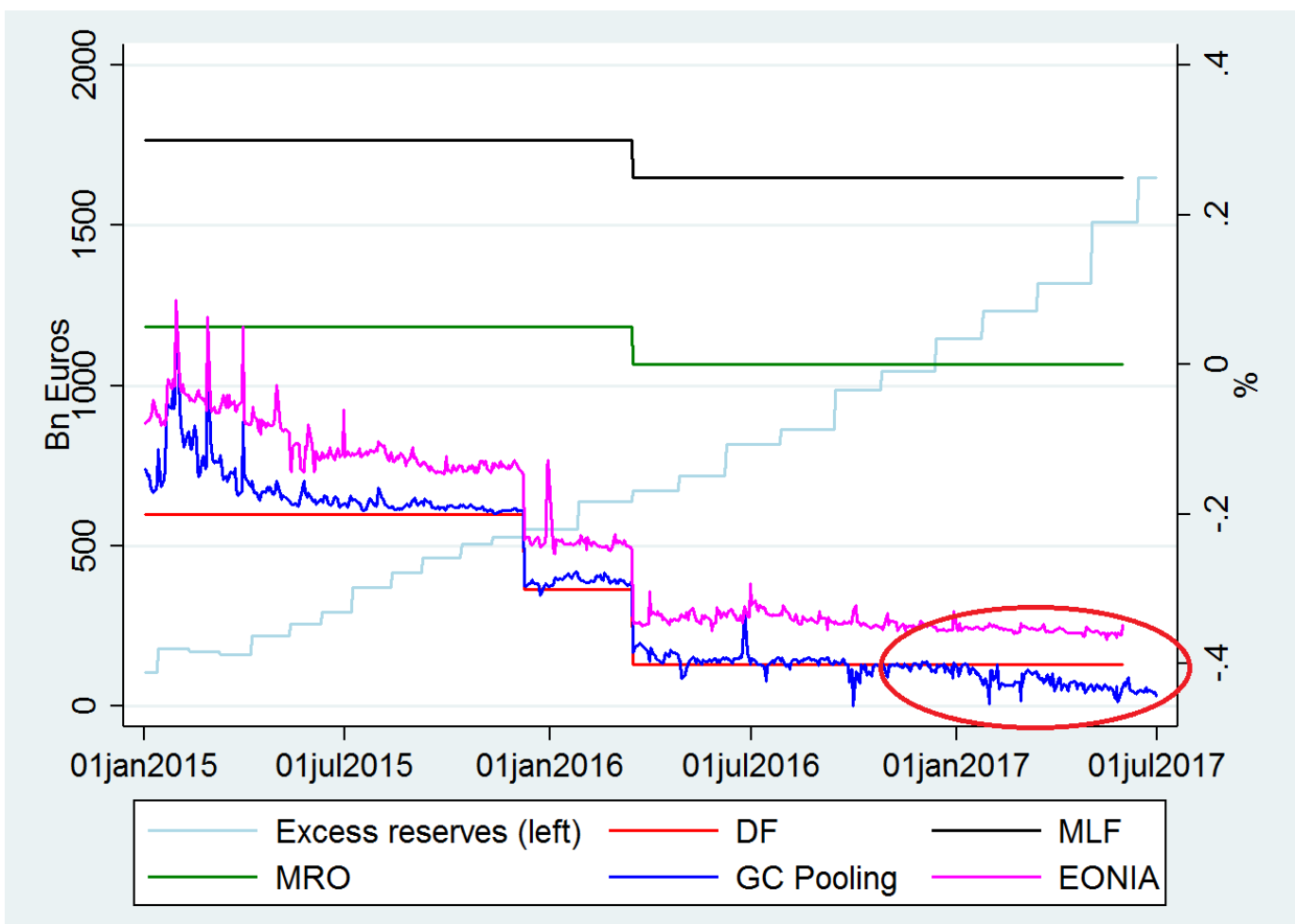

Figure 4: Excess reserves and interest rates.

Both Eonia and GC-Pooling rates are daily aggregate weighted-average rates. Monetary policy interest rates: DF deposit facility; MLF - Marginal lending facility; MRO - main refinancing operations.

The central bank unconventional liquidity provision through long-term refinancing operations in 2011-2012 and the Eurosystem's asset purchases programme (APP) increases excess reserves and has a double effect on money markets: first, increase in excess reserves reduces value of cash and therefore drives both interest rates down; second, high amounts of liquidity provided against collateral reduce its aggregate level, increasing its price, thus bringing repo rates even lower. Unlike unsecured rates, repo rates are not bounded below by the deposit facility rate.

\section{Model}

We extend the standard framework for banks' demand for reserves by introducing an interbank secured market and counterparty risk in the unsecured market. We follow Poole (1968) and envision a frmework where risk-neutral banks seek to manage their end-of-day reserve position during the 
day by trading on both markets. The model consists of three periods. At dawn, banks start the day holding heterogeneous reserves. During the day, interbank markets open and banks are allowed to trade on both secured and unsecured markets. In the evening, banks are subject to a late settlement shock when markets are closed. For simplicity, we set reserve requirements to zero, and therefore reserves and excess reserves are equivalent. At the end of the day, banks deposit positive excess reserves at the central bank or borrow at the lending facility if excess reserves are negative. Figure 5 presents the timing of the model:

\begin{tabular}{ccc} 
Dawn & Midday & Dusk \\
\hline & & \\
Aggregate reserves $m$ & Interbank trading $\left(q_{u}, q_{s}\right)$, rates $\left(r_{u}, r_{s}\right)$ & Settlement shock $\tilde{\epsilon}$ \\
Payment shock $\pm \nu$ & Collateral constraint $b_{0}>q_{s}$ & Deposit/lending facility \\
Initial bonds $b_{0}$ & Interbank markets close & to fulfil reserve requirements \\
& & Profits are consumed
\end{tabular}

Figure 5: Time-line

\subsection{Interbank markets}

Banks can trade on unsecured and secured markets with respective quantities $q_{u}$ and $q_{s}$. Borrowers in the unsecured market are subject to counterparty risk. A lender gains $q_{u} r_{u}$ with probability $p$ and loses $-q_{u}$ with probability $1-p$.

Trading in the secured market implies an exchange of cash against collateral. Collateral is risk free, hence haircuts are absent. Secured lenders face neither counterparty nor collateral risk, and therefore gain $q_{s} r_{s}$ in any state. On the other hand, in order to protect lenders against counterparty risk, borrowers pledge $q_{s}$ units of collateral from their bond holdings when borrowing on the secured market.

\subsection{Banks}

Banks are risk neutral, and behave competitively. The payment shock $\pm \nu$ defines two types of banks. With probability $\frac{1}{2}$, a bank is subject to a positive shock $\nu$ on its reserves. With probability $\frac{1}{2}$, a bank is subject to a negative payment shock $-\nu$ on its reserves. This shock is independent from the settlement shock $\tilde{\epsilon}$. Banks facing a negative shock borrow (type $B$ ) on money markets while banks facing a positive shock become lenders (type $L$ ).

Banks initially hold $m>0$ units of excess reserves. In line with Poole (1968) and subsequent work on the transmission of monetary policy to interbank markets, each bank is subject to a late settlement shock $\tilde{\epsilon}$ in period 2. In the model, banks trade to insure against the settlement shock which occurs after the closure of the markets. Excess reserves after the settlement shock are: 


$$
\begin{array}{r}
m+\nu-q+\tilde{\epsilon}_{L}, \text { for each lender } \mathrm{L} \\
m-\nu+q+\tilde{\epsilon}_{B}, \text { for each borrower B }
\end{array}
$$

End-of-day reserve position, or excess reserves, is the sum of initial holdings $m$, payment shocks $\pm \nu$, quantities exchanged on interbank markets $q=q_{u}+q_{s}$, and the late settlement shock $\tilde{\epsilon}$. The settlement shock is drawn from a cumulative distribution function $F$ centred on zero mean with full support over $\mathbb{R}$. Banks place positive excess reserves at the deposit facility while turning to the lending facility if they run negative excess reserves. Interest rates at standing facilities are respectively $r_{d}$ (deposit) and $r_{p}$ (lending). All banks enjoy the same access to the central bank facilities.

Banks hold an initial amount $b_{0}$ of bonds. Trading in the secured market reduces the quantity of bonds held by borrowers while it increases the one of lenders. Both borrowers and lenders derive a positive concave increasing profit $K($.$) from holding bonds. This comes from various motives.$ First, banks may serve better their customers' needs when holding available bonds and therefore earning profits by attracting more customers (see more on imperfect competition between dealers in the market for securities in Amihud and Mendelson (1986) and Ho and Stoll (1983)). Second, banks that engage in short-selling may avoid buying bonds at a higher price when holding a certain amount on their book (more on repo specialness in Duffie (1996) and Jordan and Jordan (1997)). Finally, bonds can pay the convenience premium as in Krishnamurthy and Vissing-Jorgensen (2012) and Casassus and Collin-Dufresne (2005).

Furthermore, borrowers must hold a positive quantity of bonds (collateral constraint):

$$
b_{0}-q_{s} \geq 0
$$

Borrowers' profits are

$$
\tilde{W}_{B}=-r_{u} q_{u}-r_{s} q_{s}+K\left(b_{0}-q_{s}\right)+\left(\tilde{\epsilon}-\hat{\epsilon}_{B}\right)\left(\mathbf{1}_{\tilde{\epsilon} \geq \hat{\epsilon}_{B}} r^{d}+\mathbf{1}_{\tilde{\epsilon}<\hat{\epsilon}_{B}} r^{p}\right)
$$

with $\hat{\epsilon}_{B}=-m+\nu-q$. Conversely, lenders' profits are

$$
\tilde{W}_{L}=\tilde{\delta} r_{u} q_{u}-(1-\tilde{\delta}) q_{u}+r_{s} q_{s}+K\left(b_{0}+q_{s}\right)+\left(\tilde{\epsilon}-\hat{\epsilon}_{L}\right)\left(\mathbf{1}_{\tilde{\epsilon} \geq \hat{\epsilon}_{L}} r^{d}+\mathbf{1}_{\tilde{\epsilon}<\hat{\epsilon}_{L}} r^{p}\right)
$$

with $\hat{\epsilon}_{L}=-m-\nu+q$ and $\tilde{\delta}=1$ with probability $p, 0$ otherwise. Profits are the sum of interest rates paid/received on quantities borrowed, profits from holding unpledged bonds, and proceeds from reserve management at the central bank. In the end, bank $i=\{B, L\}$ maximizes its expected profits conditional on its collateral constraint (which applies to borrowers only). 


$$
\begin{aligned}
& \max _{\left(q_{u}, q_{s}\right)} \mathbb{E}\left[\tilde{W}_{i}\right] \\
& \begin{cases}q_{u} \geq 0 & \left(\lambda_{u}\right) \\
q_{s} \geq 0 & \left(\lambda_{s}\right) \\
\left(b_{0}-q_{s}\right) \mathbf{1}_{i \in B} \geq 0 & \left(\mu_{B}\right)\end{cases}
\end{aligned}
$$

\subsection{Equilibrium}

We derive the first order conditions and characterize the equilibrium in both markets.

Banks cannot borrow on one market while lending on the other because (i) the heterogeneity $\pm \nu$ is symmetric across borrowers and lenders and is the only motive for trade, and (ii) the opportunity cost of collateral is symmetric across banks.

\subsubsection{Borrowers' demand for funding}

The first order conditions of the optimization program 3.6 for borrowers are:

$$
\begin{aligned}
-r_{u}+r_{d}+\left(r_{p}-r_{d}\right) F(-m+\nu-q)+\lambda_{u, B} & =0 \\
-r_{s}-K^{\prime}\left(b_{0}-q_{s}\right)+r_{d}+\left(r_{p}-r_{d}\right) F(-m+\nu-q)+\lambda_{s, B} & =0 \\
\mu_{B}\left(b_{0}-q_{u}\right) & =0 \\
\lambda_{u, B} q_{u} & =0 \\
\lambda_{s, B} q_{s} & =0
\end{aligned}
$$

Using the complementary slackness conditions, we show that borrowers address no demand in interbank markets if rates are high:

$$
\begin{array}{r}
r_{u} \geq r_{u, B}\left(q_{s}\right)=r_{d}+\left(r_{p}-r_{d}\right) F\left(-m+\nu-q_{s}\right) \\
r_{s} \geq \bar{r}_{s, B}\left(q_{u}\right)=K^{\prime}\left(b_{0}\right)+r_{d}+\left(r_{p}-r_{d}\right) F\left(-m+\nu-q_{u}\right)
\end{array}
$$

Likewise, borrowers pledge all their collateral in order to borrow in the secured market if rates are low:

$$
r_{s} \leq \underline{r}_{s, B}=K^{\prime}(0)+r_{d}+\left(r_{p}-r_{d}\right) F\left(-m+\nu-q_{u}\right) .
$$

These results stem from the first order conditions applied to borrowers. Borrowers trade off benefits and costs to borrow in the unsecured market: they insure against going to the lending facility (at a penalty rate) when reserves are low. Therefore, the demand for insurance decreases as unsecured 
interest rate increases. As soon as unsecured rates are too high, it is not worth borrowing on the unsecured market, the demand for unsecured borrowing falls to zero. The interior solution is defined when interest rates is equal to the marginal benefit, which is the deposit facility rate plus the expected savings of not borrowing at the penalty rate.

Likewise, borrowers address no demand in the secured market if the cost of borrowing exceeds the benefits of not going to the lending facility. However, borrowing on the secured market is bounded above by the quantity of available collateral (collateral constraint). Unlike for the unsecured borrowing, the marginal benefits consists of a cash leg, expected savings of not going to the lending facility, and a collateral leg, marginal benefit of holding collateral. Demand for secured funding is bounded above by the quantity of available collateral, even if marginal benefits exceed marginal costs at $q_{s}=b_{0}$.

\subsubsection{Lenders' supply of funding}

First order conditions for lenders are:

$$
\begin{aligned}
-p r_{u}+(1-p)+r_{d}+\left(r_{p}-r_{d}\right) F(-m-\nu+q)-\lambda_{u, L} & =0 \\
-r_{s}-K^{\prime}\left(b_{0}+q_{s}\right)+r_{d}+\left(r_{p}-r_{d}\right) F(-m-\nu+q)-\lambda_{s, B} & =0 \\
\lambda_{u, L} q_{u} & =0 \\
\lambda_{s, L} q_{s} & =0
\end{aligned}
$$

Lenders do not supply reserves in interbank markets if interest rates are low:

$$
\begin{array}{r}
r_{u} \leq r_{u, L}\left(q_{s}\right)=\frac{1}{p}\left(1-p+r_{d}+\left(r_{p}-r_{d}\right) F\left(-m-\nu+q_{s}\right)\right) \\
r_{s} \leq r_{s, L}\left(q_{u}\right)=K^{\prime}\left(b_{0}\right)+r_{d}+\left(r_{p}-r_{d}\right) F\left(-m-\nu+q_{u}\right)
\end{array}
$$

Developed arguments are similar to the borrower's case. It is not profitable to supply funding when rates are low and do not compensate for the increased risk to borrow from the lending facility. In the secured market, marginal benefits as for borrowers include a cash leg, and a collateral leg, the marginal benefit of holding additional unpledged collateral $K^{\prime}($.$) .$

\subsubsection{Competitive equilibrium}

To derive the competitive equilibrium, we proceed in steps. First, using the participation rates established above, we derive the demand functions in the appendix 6.3. Second, we define the competitive equilibrium. Third, we prove its existence and characterize interior and corner solutions. Finally, we prove its uniqueness using the gross substitute property. 
Definition 3.1 (Competitive equilibrium). A competitive equilibrium on interbank markets is defined as exchanged quantities $\left(q_{u}, q_{s}\right)$ and interest rates $\left(r^{u}, r^{s}\right)$ such that:

- Given initial reserves $m \pm \nu$, borrowers and lenders maximize their expected profits following the program 3.6,

- Markets clear,

Theorem 3.1 (Existence). The competitive equilibrium defined in 3.1 exists.

Proof. Banks have strict convex preferences over convex sets, providing a sufficient condition for the existence of the competitive equilibrium.

As soon as there is some counterparty risk, we show that (i) banks do not perfectly insure against their payment shock, and (ii) banks always exchange positive quantities on the secured market.

Lemma 3.1 (Aggregate interbank volume). If $p=1$, then

$$
q=\nu
$$

If $p<1$, then

$$
q<\nu
$$

Proof. The proof is detailed in Appendix 6.4.

Because of counterparty risk and the opportunity cost of collateral, banks do not perfectly share reserves. This result stands in line with models of monetary policy implementation like in Bech and Monnet (2016), where frictions come from the matching process or transaction costs.

Lemma 3.2. If $p=1$ then

$$
q_{s}=0 .
$$

If $p<1$ then

$$
q_{s}>0 .
$$

Proof. Assume $q_{s}=0$. It follows, $\bar{r}_{s, B} \leq r_{s, L}$.

$$
\bar{r}_{s, B} \leq r_{s, L} \Leftrightarrow\left(r_{p}-r_{d}\right)(F(-m+\nu-q)-F(-m-\nu+q)) \leq 0
$$

This inequality cannot hold due to lemma 3.1. 
From lemma 3.2 and the collateral constraint (3.3), we characterize in appendix 6.5 the four types of equilibria that can arise depending on whether there is trade or not in the unsecured market, and whether the collateral constraint is binding or not.

Theorem 3.2 (Uniqueness). The competitive equilibrium defined in 3.1 is unique.

Proof. By definition, two equilibria from proposition 6.1 cannot correspond to two different cases. If there are two equilibria from two different cases, we can show one is dominated by the other. Cases 1,2 and 4 correspond to corner solutions in which the equilibrium is unique. Mappings defined by the systems (6.23), (6.24) and (6.26) are (i) self-maps, (ii) defined in compact closed sets, (iii) continuous and (iv) strictly increasing.

Regarding case 3, we prove in appendix 6.6 that excess demands in unsecured and secured markets satisfy the gross substitutes property, which is a sufficient condition for uniqueness of the competitive equilibrium in this case.

Remark 3.1. Using proposition 6.5 We can show it is possible to pin down the equilibrium using one market only, this would be equivalent to full counterparty risk, $p=0$, or an infinitely concave opportunity cost of collateral at $b_{0}$.

\subsection{Discussion of assumptions}

We discuss the simplifying assumptions. First, withdrawals of reserves are the only source of heterogeneity in this framework. This assumption stands as the only motive for trade in interbank markets and implies results in line with reported stylized facts. However, other heterogeneities in these two money markets could constitute other motives for trade. These include mainly heterogeneous holdings of bonds $b_{0}$ as well as heterogeneous profits from holding unpledged bonds $K($.$) . With these assumptions, there could exist banks lending in the secured market and borrowing$ in the unsecured market if their lack of bonds exceeds their lack of reserves. We also assume collateral is risk-free. Haircuts could easily be added to our framework to reflect collateral risk.

The opportunity cost of collateral is a necessary condition in our model to pin down the stylized fact 3. Indeed, lenders must derive a positive expected profit from lending in the secured market. The opportunity cost of collateral provided this additional profit that allow them to lend even if rates are below the deposit facility rate.

\section{Results}

We draw the main results of the model in three parts. First, we discuss the substitution between secured and unsecured interbank markets resulting from changes in the counterparty risk and 
monetary policy (stylized facts 1 and 2). Second, we provide bounds for interest rates in both secured and unsecured markets (stylized fact 3) and study the impact of monetary policy on the interbank rates. Finally, we discuss predictions of the model on the different impacts of monetary policies that use as instruments only change in excess reserves and change in both excess reserves and marketable collateral. And we test theses predictions empirically.

\subsection{Coexistence between unsecured and secured markets}

These results are in line with stylized fact 1: banks may borrow on both markets, even if their collateral constraint is not binding.

For simplicity, assume that the initial bond holdings are smaller than the payment shock.

From proposition 6.1, we know banks trade on both markets if (i) the counterparty risk is low enough ( $p$ is high) and if (ii) the gain from trade $\left(r_{p}-r_{d}\right)(F(-m+\nu-q)-F(-m-\nu+q))$ is high enough. We study separately how changes in the counterparty risk and gains from trade, in particular, aggregate excess reserves $m$, affect the substitution between both markets.

Proposition 4.1 (Substitution and counterparty risk).

Holding all parameters except $p$ fixed,

1. If $\left(r_{p}-r_{d}\right)\left(F\left(-m+\nu-b_{0}\right)-F\left(-m-\nu+b_{0}\right)\right) \geq K^{\prime}(0)-K^{\prime}\left(2 b_{0}\right)$ then:

$$
\exists \underline{p}, \bar{p} \in(0,1) \text { such that } \begin{cases}q_{u}=0 \text { and } q_{s}=b_{0} & \text { for } p \leq \underline{p} \\ q_{u}>0 \text { and } q_{s}=b_{0} & \text { for } \underline{p}<p \leq \bar{p} \\ q_{u}>0 \text { and } q_{s}<b_{0} & \text { for } \underline{p}<p<1 \\ q_{u}=\nu \text { and } q_{s}=0 & \text { for } p=1\end{cases}
$$

2. If $\left(r_{p}-r_{d}\right)\left(F\left(-m+\nu-b_{0}\right)-F\left(-m-\nu+b_{0}\right)\right)<K^{\prime}(0)-K^{\prime}\left(2 b_{0}\right)$ then:

$$
\exists \hat{p} \in(0,1) \text { such that } \begin{cases}q_{u}=0 \text { and } q_{s}<b_{0} & \text { for } p \leq \hat{p} \\ q_{u}>0 \text { and } q_{s}<b_{0} & \text { for } \hat{p}<p<1 \\ q_{u}=\nu \text { and } q_{s}=0 & \text { for } p=1\end{cases}
$$

Furthermore,

$$
\frac{\partial q_{u}}{\partial p} \geq 0 \text { and } \frac{\partial q_{s}}{\partial p} \leq 0
$$

Proof. The proof is detailed in appendix 6.7 .

Figure 6 summarizes the effects of the counterparty risk on volumes. Figures $6 \mathrm{a}$ and $6 \mathrm{~b}$ illustrate respectively cases 1 and 2 in proposition 4.1. Case 1 corresponds to the relatively high levels of gain 
from trade, when, for example, excess reserves are low and cash is relatively expensive. If there is no counterparty risk, banks have no incentives to trade on the secured market. Therefore they trade only on the unsecured and perfectly share their payment shocks as in the frictionless case of Poole (1968). If counterparty risk is relatively low, then both markets are active, and the interest rate in the unsecured market is sufficiently low for borrowers in order to borrow on the unsecured market and not to pledge all their collateral to borrow on the secured one. When counterparty risk increases even more, borrowers have to go to the secured market but they are constrained by their available collateral. Thus they fully pledge their collateral but still continue to borrow in the unsecured market. At some point, the counterparty risk becomes too high and prevents funding in the unsecured market.

Case 2 reflects the situation when gains from trade decrease due to, for example, increase in excess reserves. In this situation, because cash is relatively cheaper and collateral is relatively more expensive banks never fully pledge their collateral whatever the level of counterparty risk is. For the remaining, the dynamics is similar to the previous case: when the unsecured market is frictionless banks can borrow up to the level of the payment shock; when counterparty risk is higher, banks borrow on both markets; and when the risk is too high, banks go to the secured market but do not pledge their full collateral.

Finally, smaller counterparty risk increases volumes on the unsecured market and decreases on the secured one while increasing aggregate volumes. Indeed, the two markets are not perfect substitutes therefore relaxing the friction of counterparty risk while holding the gains from trade constant raises the overall volume.

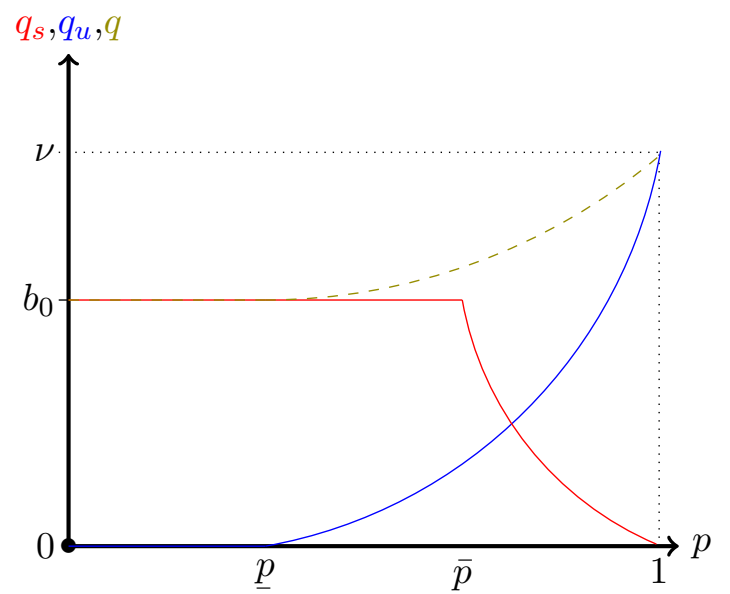

(a) Case (1)

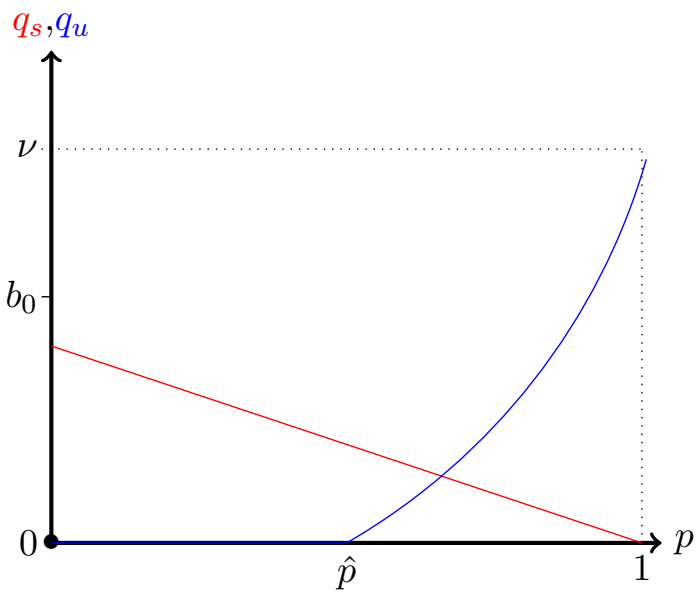

(b) Case (2)

Figure 6: $q$ as a function of $p$

Proposition 4.2 (Substitution and excess reserves). Holding all parameters except $m$ fixed,

1. If $p=1$, then $q_{u}=\nu$ and $q_{s}=0$ for $m \geq 0$,

2. If $p<1$, then: 
(a) If $q_{u}(m=0)>0$ and $q_{s}(m=0)=b_{0}$ then:

$$
\exists \underline{m}, \bar{m}>0 \text { such that } \begin{cases}q_{u}>0 \text { and } q_{s}=b_{0} & \text { for } 0 \leq m \leq \underline{m} \\ q_{u}>0 \text { and } q_{s}<b_{0} & \text { for } \underline{m}<m<\bar{m} \\ q_{u}=0 \text { and } q_{s}<b_{0} & \text { for } \bar{m} \leq m\end{cases}
$$

(b) If $q_{u}(m=0)>0$ and $q_{s}(m=0)<b_{0}$ then:

$$
\exists \hat{m}>0 \text { such that } \begin{cases}q_{u}>0 \text { and } q_{s}<b_{0} & \text { for } 0 \leq m<\hat{m} \\ q_{u}=0 \text { and } q_{s}<b_{0} & \text { for } \hat{m} \leq m\end{cases}
$$

(c) If $q_{u}(m=0)=0$ and $q_{s}(m=0)<b_{0}$ then:

$$
q_{u}=0 \text { and } q_{s}<b_{0} \text { for } m \geq 0 .
$$

Furthermore,

$$
\frac{\partial q_{u}}{\partial m} \leq 0 \text { and } \frac{\partial q_{s}}{\partial m} \leq 0
$$

Proof. The proof is detailed in appendix 6.8. The cases above are a direct application of proposition 6.1 knowing quantities exchanged decrease with excess reserves $m$.

Excess reserves have different effects on the markets given the level of counterparty risk. When the unsecured market is frictionless, banks can fully insure against liquidity shock by borrowing on this market whatever the level of excess reserves. When counterparty risk is non-zero, figure 7 illustrates the effects of excess reserves on the substitution between secured and unsecured markets. Figure 7a corresponds to the case when both markets are active, and banks pledge all their collateral at $m=0$ due to, for example, high level of counterparty risk. When excess reserves are low, banks borrow on both markets and up to the collateral constraint on the secured market. With increase in excess reserves, banks reduce their borrowing on both markets and stop saturating their collateral constraint. As excess reserves rise even higher, banks stop borrowing on the unsecured market but continue borrowing a non-zero amount on the secured one.

Figure $7 \mathrm{~b}$ discusses the case when banks never saturate their collateral constraint. In this case, banks borrow on both markets as long as excess reserves are small enough and stop borrowing on the unsecured market when excess reserves reach a certain threshold. Finally, an increase in excess reserves reduces trading volumes on both markets. 


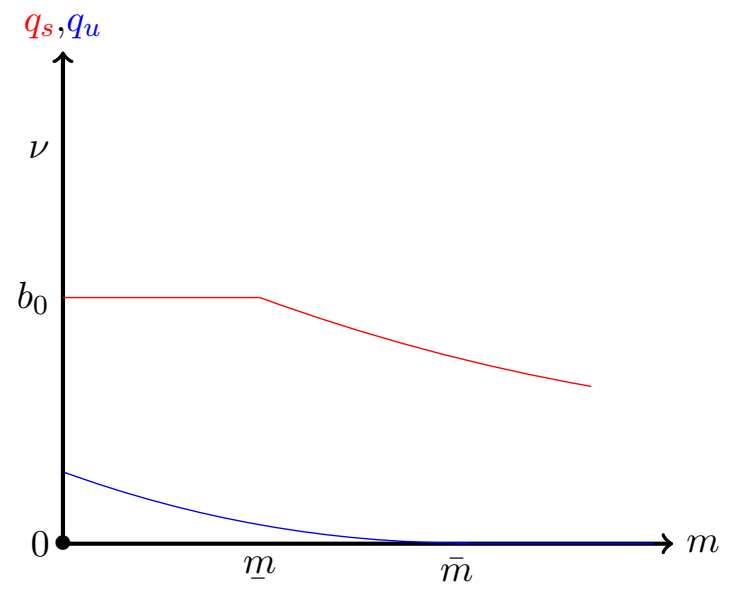

(a) Case (2.a)

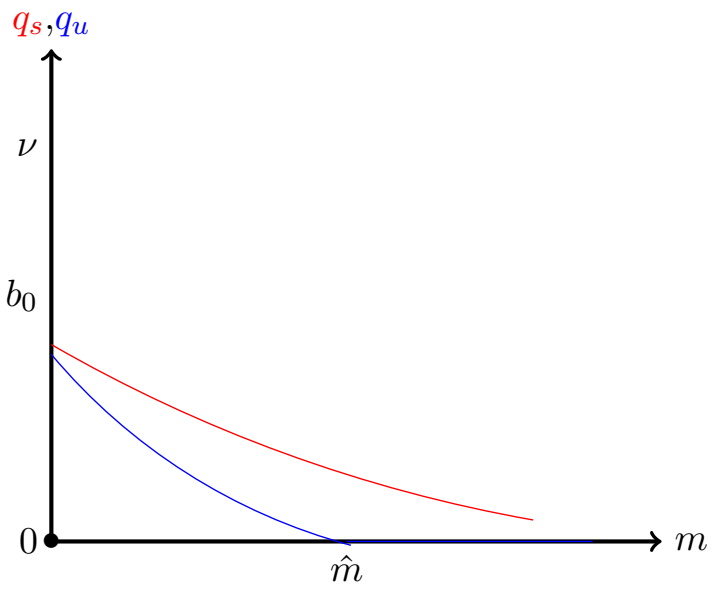

(b) Case (2.b)

Figure 7: $q$ as a function of $m$

\subsection{Monetary policy and interbank rates}

While the unsecured interest rate is bounded by the central bank corridor, the secured interest rate might fall below the deposit facility rate because of the opportunity cost of collateral (stylized fact $3)$.

Proposition 4.3 (Interest rates and the central bank corridor). Unsecured and secured interest rates are bounded by the central bank corridor and the opportunity cost to pledge collateral.

$$
\left\{\begin{array}{l}
r^{u} \in\left(\frac{r_{d}+1-p}{p}, r^{p}\right) \\
r^{s} \in\left(r^{d}-K^{\prime}\left(b_{0}\right), r^{p}-K^{\prime}(0)\right)
\end{array}\right.
$$

Proof. If unsecured interest rates exceed the penalty rate, banks could borrow an infinite amount from the central bank and lend it in the interbank unsecured market. Respectively, if unsecured rates are below the deposit facility corrected by the counterparty risk, banks could borrow from the interbank market and lend to the central bank.

Conversely, if secured interest rates plus the opportunity cost to pledge collateral (given no trade in the secured market) are below the deposit facility rate, banks can borrow in the secured market in order to lend at the central bank. If secured interest rates plus the opportunity cost of collateral (given no collateral) are higher than the penalty rate, banks can borrow from the central bank and lend in the secured market.

We continue by investigating the effect of excess reserves on interbank interest rates. We restrict the analysis to the most interesting case when both markets are active and the collateral constraint is not binding. We first notice that an increase in excess reserves reduces aggregate quantities traded on interbank markets, that is: 


\section{Lemma 4.1.}

$$
\frac{\partial q}{\partial m} \in(-1,0)
$$

Proof. We have

$$
\frac{\partial q}{\partial m}=\frac{f(-m-\nu+q)-p f(-m+\nu-q)}{f(-m-\nu+q)+p f(-m+\nu-q)}
$$

Thus, $0>\frac{\partial q}{\partial m}>-1$.

Increasing excess reserves reduces the overall gain from trade. Frictions such as counterparty risk and the opportunity cost of collateral prevent perfect sharing of reserves. Therefore, an increase in excess reserve is not perfectly channelled to volumes, and their reduction is smaller than 1 . This Lemma allows us to study the marginal effect of excess reserves on interest rates. We show that increasing the amount of excess reserves $m$ reduces interest rates in both secured and unsecured markets (stylized fact 3):

Proposition 4.4. The marginal effect of excess reserves $m$ on interest rates is negative:

$$
\left\{\begin{array}{l}
\frac{\partial r_{u}}{\partial m}=\left(-1-\frac{\partial q}{\partial m}\right)\left(r_{p}-r_{d}\right) F(-m+\nu-q)<0 \\
\frac{\partial r_{s}}{\partial m}=\left(-1-\frac{\partial q}{\partial m}\right)\left(r_{p}-r_{d}\right) F(-m+\nu-q)-\frac{\partial q_{s}}{\partial m} K^{\prime \prime}\left(b_{0}-q_{s}\right)<0
\end{array}\right.
$$

Proof. We use the first order conditions of borrowers.

Increasing in the amount of excess reserves decreases the gain from sharing reserves, which decreases interest rates in both unsecured and secured markets. On top of that, secured interest rates are subject to an additional effect due to the opportunity cost of collateral. In other words, higher level of excess reserves in the market makes cash relatively cheaper and collateral relatively more expensive leading to a decrease in secured interest rates.

Example 4.1. Figure 8 presents the inverse demands as functions of excess reserves $m$. In line with previous contributions, interest rates in both markets decrease with excess reserves. The figure also stresses some predictions from our model. First, there is no exchange in the unsecured market when excess reserves move away from zero because of counterparty risk (see proposition 4.2). The counterparty risk makes trading in the unsecured market less profitable than borrowing/lending at the central bank. Thus, trading only occurs in the secured market when excess reserves are far from zero. Second, the spread between unsecured and secured interest rates is positive. Third, secured interest rates can go below the deposit facility rate when excess reserves are large. 


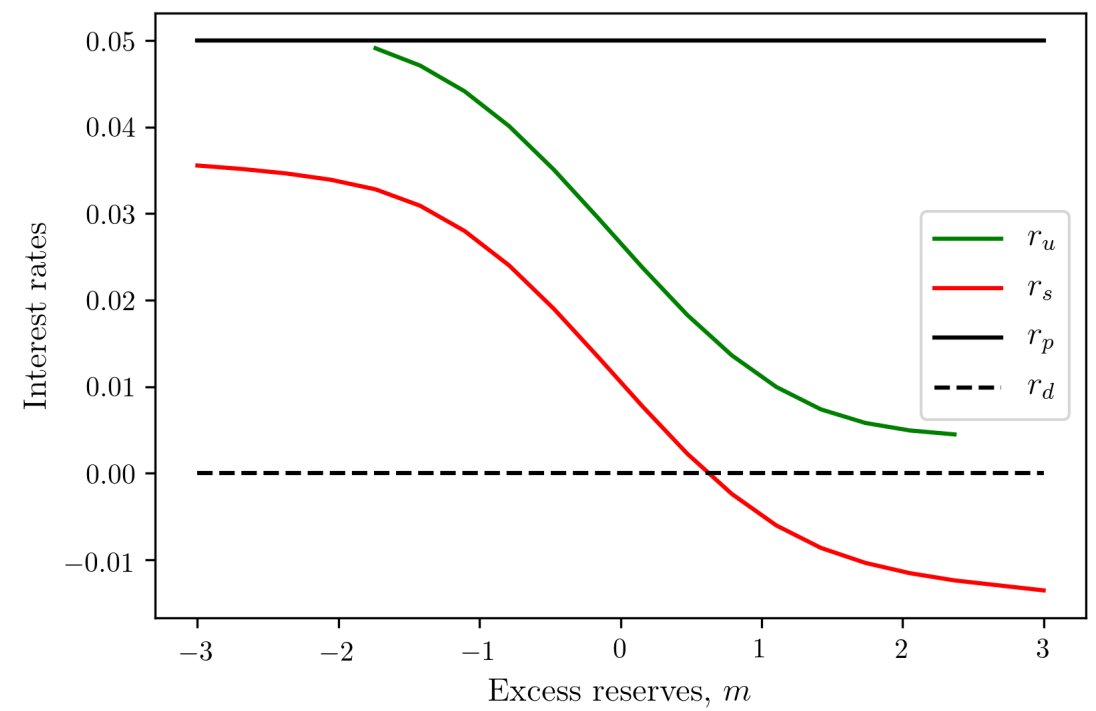

Figure 8: Inverse demand for unsecured and secured funding.

We use the parameters from example 4.17. Unsecured interest rates are not presented on the graph if there is no exchange in the unsecured market.

\subsection{Effects of different monetary policies on interbank volumes and rates}

In this section we imagine two types of monetary policies: one which alters only excess reserves, $m$, and the other that affects both excess reserves, $m$, and the level of available collateral, $b 0$. The first policy $M P 1$ can be vaguely associated with the 3-year (very) long-term refinancing operations (VLTROs), implemented by the ECB in December 2011 and February 2012. The operations consist in lending to the banks about 1 trillion euros in two tranches in December 2011 and February 2012 against a large basket of collateral. Since banks decide themselves which collateral to use for these operations, and the ECB accepts also non-marketable collateral such as credit claims, we can approximately consider that the VLTROs essentially increased only excess reserves without producing scarcity of available marketable assets. The second monetary policy $M P 2$ corresponds to the Eurosystem's asset purchases programme (APP) that consists in buying assets, in particular sovereign bonds, from the market. Such a policy provides liquidity (increases excess reserves $m$ ) but also reduces the available marketable collateral which stands for $b_{0}$ in our model. We compare how these two monetary policies affect interbank volumes, interest rates and the spread between the secured and unsecured rates.

We first prove that the two policies have the same effect on the change in aggregate volumes but they cause a change in the substitution between the two markets. Still, we restrict the analysis to the case in which both markets are active and the collateral constraint is not binding.

Proposition 4.5. Both monetary policies have the same effect on aggregate volumes:

$$
q_{M P 1}^{\prime}=q_{M P 2}^{\prime} .
$$


Marginal changes in interbank volumes depend on the change in the opportunity cost of collateral:

$$
\begin{aligned}
& q_{s, M P 2}^{\prime}=q_{s, M P 1}^{\prime}+\frac{K^{\prime \prime}\left(b_{0}+q_{s}\right)-K^{\prime \prime}\left(b_{0}-q_{s}\right)}{K^{\prime \prime}\left(b_{0}+q_{s}\right)+K^{\prime \prime}\left(b_{0}-q_{s}\right)} \\
& q_{u, M P 2}^{\prime}=q_{u, M P 1}^{\prime}-\frac{K^{\prime \prime}\left(b_{0}+q_{s}\right)-K^{\prime \prime}\left(b_{0}-q_{s}\right)}{K^{\prime \prime}\left(b_{0}+q_{s}\right)+K^{\prime \prime}\left(b_{0}-q_{s}\right)}
\end{aligned}
$$

Proof. To establish the first result, note that the change in the aggregate volume does not depend on $b_{0}$ :

$$
q^{\prime}=\frac{f(-m-\nu+q)-p f(-m+\nu-q)}{f(-m-\nu+q)+p f(-m+\nu-q)}
$$

To establish the second result, differentiate the market clearing condition in the secured market.

As the market clearing condition in the unsecured market suggests, the change in aggregate interbank volumes only depends on the change in aggregate reserves, and not on the change in the amount of marketable collateral. Indeed, given that the two markets are active and that the collateral constraint is not binding, a change in the amount of marketable collateral does not move the aggregate volume since the aggregate volume is driven by liquidity, i.e. the amount of aggregate reserves. The result would change if the collateral constraint was saturated.

However, the type of monetary policy affects the substitution between the two markets. The change in substitution depends on the marginal opportunity cost of collateral. Indeed, the second type of monetary policy $M P 2$ reduces the quantity $b_{0}$. As a consequence, the opportunity cost of collateral $K^{\prime}\left(b_{0}-q_{s}\right)$ increases. The change in the substitution depends on the curvature of $K$, i.e. the marginal opportunity cost of collateral. For example, if the marginal opportunity cost of collateral increases, then borrowers are more sensitive to a change in the amount of marketable collateral than lenders, and are reluctant to give up their collateral. Hence, volumes in the secured market relatively decline with respect to the first type of monetary policy.

Now we study how the two monetary policies affect the interest rates.

Proposition 4.6. The two monetary policies similarly impact the unsecured rate:

$$
r_{u, M P 2}^{\prime}=r_{u, M P 1}^{\prime}
$$

The secured rate relatively decreases when the central bank purchases marketable collateral (MP2):

$$
r_{s, M P 2}^{\prime}=r_{s, M P 1}^{\prime}+\frac{2 K^{\prime \prime}\left(b_{0}+q_{s}\right) K^{\prime \prime}\left(b_{0}-q_{s}\right)}{K^{\prime \prime}\left(b_{0}+q_{s}\right)+K^{\prime \prime}\left(b_{0}-q_{s}\right)} .
$$

Proof. Differentiate first order conditions of borrowers using the results from proposition 4.5. 
The two types of monetary policy, $M P 1$ and $M P 2$ have a similar effect on the aggregate volume (proposition 4.5). As a consequence, the interest rate on the unsecured market, which is the rate that is purely driven by liquidity undergoes similar changes under these two monetary policies. Contrariwise, purchases of marketable collateral reduce the available collateral and increase its opportunity cost, leading to the situation when "cash chases collateral" and thus lowers the repo interest rate (this is equivalent to a higher price of collateral). Beware the second result of this proposition is achieved considering volumes $q_{s}$ are the same.

Finally we study how the two monetary policies tilt the spread between unsecured and secured interest rates. In equilibrium, first order conditions of the borrower provide us with the spread between the secured and unsecured rates:

$$
r_{u}-r_{s}=K^{\prime}\left(b_{0}-q_{s}\right) \Longrightarrow\left(r_{u}-r_{s}\right)_{M P 1}^{\prime}=-\frac{\partial q_{s, M P 1}}{\partial m} K^{\prime \prime}\left(b_{0}-q_{s}\right)<0
$$

When only excess reserves increase, $M P 1$, the spread between both markets decreases. Indeed, reducing the volumes exchanged in the secured market reduces the opportunity cost to pledge collateral, which is exactly the spread between the unsecured and the secured interest rates.

Under the monetary policy that also purchases marketable collateral, $M P 2$, the spread between the two markets increases (stylized fact 4 ). We have

$$
\left(r_{u}-r_{s}\right)_{M P 2}^{\prime}=\left(-1-q_{s, M P 2}^{\prime}\right) K^{\prime \prime}\left(b_{0}-q_{s}\right)
$$

As $q_{s, M P 2}^{\prime}<1$,

$$
\left(r_{u}-r_{s}\right)_{M P 2}^{\prime}>0
$$

Under this policy, volumes in the secured market decrease as well, but this decline is smaller than 1 in magnitude because of the frictions in the two markets. As a consequence, the reduction in marketable collateral offsets the change in the secured volumes. It increases the opportunity cost to pledge collateral, which is again the spread between the two interest rates.

Example 4.2. Figure 9 illustrates how interest rates react to the two monetary policies (see proposition 4.6. While the two monetary policies equally affect the unsecured interest rate, monetary policy MP2 further depresses secured interest rates. The spread between the two markets widens as a consequence. 


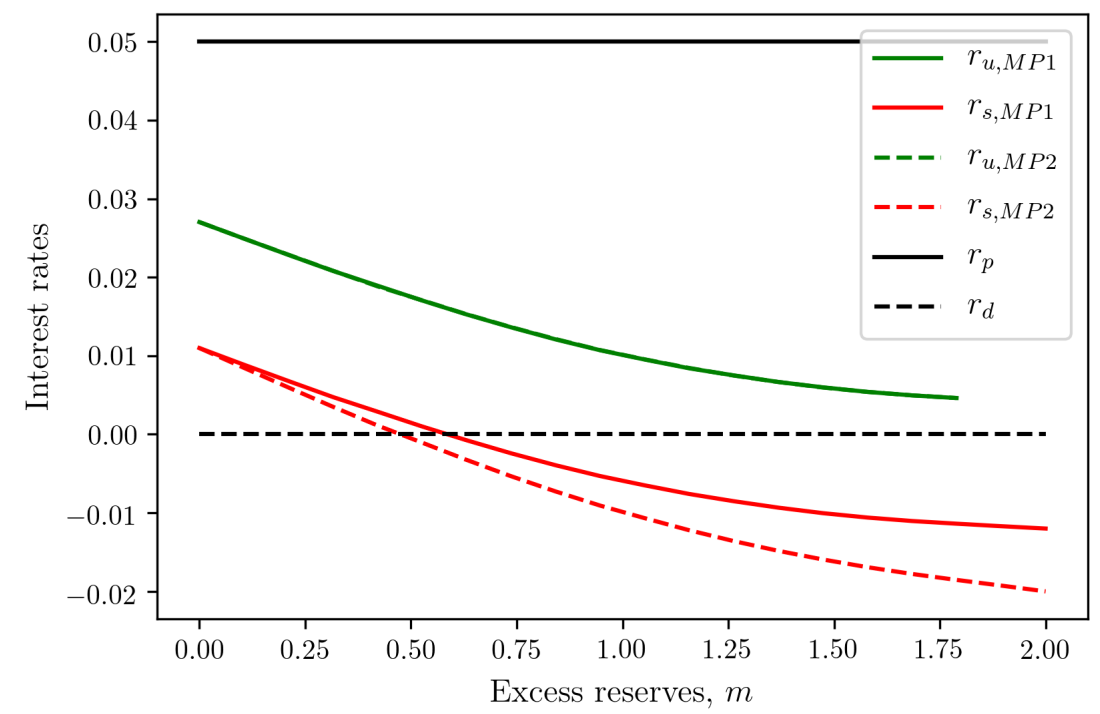

Figure 9: Inverse demand for unsecured and secured funding.

We take $r_{d}=0, r_{p}=0.05, b_{0}-\bar{g}=4, K(x) \mapsto 0.03 x-0.002 x^{2}, p=0.996, \nu=1$, and $\epsilon \sim \mathcal{N}(0,1)$. Unsecured interest rates are not presented on the graph if there is no exchange in the unsecured market.

\subsection{Empirical implications}

As discussed in the previous section, our model gives some empirical predictions on the changes in interbank rates under different monetary policies. More specifically, the model distinguishes a monetary policy regime, $M P 1$, that affects essentially the liquidity supply, and a monetary policy, $M P 2$ that affects both liquidity supply and availability of marketable collateral. In this section, we test empirically the predictions of the model:

- Both monetary policy regimes affect unsecured interest rate in the same way.

- The secured interest rate relatively decreases when the central bank increases liquidity in the market by purchasing (reducing) marketable collateral.

- The spread between the secured and unsecured rates decreases when only excess reserves increase (MP1).

- The spread between the secured and unsecured rates increases under monetary policy that purchases marketable collateral ( $M P 2)$.

Empirically, any monetary policy affects both liquidity supply and collateral base since even in the case of conventional monetary policy (MRO, LTRO), the central bank provides loans against collateral. However, the ECB accepts non-marketable collateral for its refinancing operations. This is true in particular for VLTRO (or 3 years LTRO) that aimed at easing banks' funding conditions and extended its basket of eligible collateral to include additional credit claims. The Eurosystem's Asset Purchasing Programm (APP) has a completely different design since it provides liquidity by 
purchasing marketable assets from the market, and thus significantly altering the collateral base. We associate APP with $M P 2$ in our model.

To test theses hypothesis, we use the following daily data available publicly (except GC-Eurex interest rate) that span the period from June 2008 to July 2017:

- EONIA as the unsecured interest rate;

- Weighted GC-Eurex interest rate as the secured interest rate;

- Excess liquidity defined as the sum of the deposit facility and the current account at the ECB minus the reserve requirements;

- EURIBOR-OIS spread as a proxy for counterparty risk;

- Control variables that include: ECB main interest rate (MRO), volatility VSTOXX, end-ofmaintenance period, end-of-month and end-of-quarter dummies.

We run regressions in differences of the form:

$$
\begin{aligned}
& \text { Spread }_{t}=\alpha \text { Spread }_{t-1}+\beta\left({\text { Euribor }-O I S) \text { spread }_{t}+\gamma \text { ExcessLiquidity }_{t} *[\text { ConvMP }]+}_{+}\right. \\
& \left.\delta \text { ExcessLiquidity } *[V L T R O]+\zeta V L T R O+\eta \text { ExcessLiquidity } t_{t} * A P P\right]+\theta A P P+ \\
& \kappa \text { ExcessLiquidity } *[S F C]+\lambda S F C+\text { ControlVariables }+\epsilon_{t}
\end{aligned}
$$

The main variables are taken as first differences. The dependent variable measures either spread between EONIA and GC-Eurex or spread between EONIA/GC-Eurex and deposit facility rate (DFR). Our main variables of interest are interactive variables of excess liquidity and VLTRO, APP or SFC. VLTRO is a dummy variable equal to 1 between the date of the first VLTRO, December 21, 2011, and the first date of the early repayment of the second VLTRO, February 27, 2013. APP is a dummy variable equal to 1 starting from the beginning of the program in March 13, 2015 until July 2017 (end of the sample). SFC is a dummy variable corresponding to the ECB securities-for-cash program that is equal to 1 starting from December 8, 2016 when Eurosystem central banks started accepting cash as collateral for the PSPP (Public sector purchase program) securities lending facilities. This program was an important step to ease tensions on collateral. Variable ExcessLiquidity $*[$ Conv $M P]$ corresponds to the period when no programs were active which covers the period before the first VLTRO and between the end of VLTRO and beginning of APP. Because errors may be serially correlated in these time-series regressions, we report NeweyWest standard errors and allow for up to 5 periods correlation.

Table 1 presents the results. Column 1 shows the effect of monetary policy on the spread EONIADFR. We notice that increase in excess liquidity decreases the unsecured interest rate as expected but none of the unconventional monetary policies have an additional effect. This result validates our first hypothesis that monetary policies $M P 1$ and $M P 2$ have the same effect on the unsecured interest rate.

The result is different for the secured interest rate, spread between GC-Eurex and DFR. Indeed, higher excess liquidity drives the secured interest rate down, VLTRO has no additional effect on it 
but the APP decreases in the secured interest rate even more. At the same time, introduction of securities-for-cash programm eases the tension on collateral and brings the interest rate up. This finding validates our second hypothesis.

Change in neither counterparty risk nor Vstoxx has a significant effect on the change in interest rates. The fact that counterparty risk does not explain the change in rates spread is surprising. This is certainly due to the fact that spreads are estimated as first differences. Bech and Monnet (2013) suggest a strong visual relationship between the Eonia-Euronia spread and European bank CDS spread. Therefore, we test this variable as another proxy for counterparty risk, but it is not significant either. End-of-maintenance period, end-of-month and end-of-quarter increase the changes in rates as it has been documented in the literature (Iori, De Masi, Precup, Gabbi, and Galdarelli (2008), Arrata, Nguyen, Rahmouni-Rousseau, and Vari (2017)).

Finally, column 3 shows the effect of monetary policy on the spread between unsecured and secured interest rates. We can see that the VLTRO does not have any significant effect on the spread, whereas the APP increases the spread and the CFS decreases it. At the same time, we notice that conventional monetary policy (before the VLTRO) has a significant positive effect on the spread suggesting that even in the absence of direct purchases of marketable collateral, monetary policy is not neutral to the collateral base. All in all, the empirical findings support the model prediction that central bank asset purchases positively and significantly affect the spread between unsecured and secured interest rates. However, due to the operational set-up of monetary policy, we are not able to confirm the hypothesis that the monetary policy solely increasing the liquidity supply decreases the spread. 
Table 1: Effect of excess reserves on spread between GC-Pooling repo and EONIA interest rates.

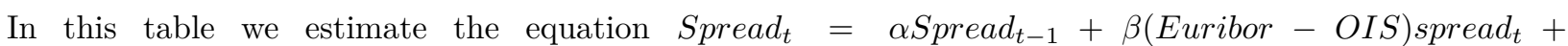
$\gamma$ ExcessLiquidity $*[$ ConvMP $]+\delta$ ExcessLiquidity ${ }_{t} *[$ VLTRO $]+\zeta$ VLTRO $+\eta$ ExcessLiquidity $_{t} *\left[\right.$ APP $^{2}+$ $\theta A P P+\kappa$ ExcessLiquidity $*[S F C]+\lambda S F C+$ ControlVariables $+\epsilon_{t}$ using daily time series data from June 2008 to July 2017. Euribor-OIS spread and Vstoxx are control variables that control for counterparty risk and general market conditions respectively. VLTRO is a dummy variable equal to 1 between December 21, 2011 and February 27, 2013. APP is a dummy variable equal to 1 starting from the beginning of the program in March 13, 2015 until July 2017. SFC is a dummy variable corresponding to the ECB securities-for-cash program that is equal to 1 starting from December 8, 2016 when Eurosystem central banks started accepting cash as collateral for the PSPP (Public sector purchase program) securities lending facilities. Variable ExcessLiquidity $*[$ Conv $M P]$ corresponds to the period when no programs were active which covers the period before the first VLTRO and between the end of VLTRO and beginning of APP. MRO is the level of ECB main interest rate. End-of-maintenance period, end-of-month and end-of-quarter are dummies corresponding to 1 at the end of the maintenance period, month and quarter. In parentheses, we report Newey-West standard errors with up to 5 periods correlation. ${ }^{*},{ }^{* *}$, and ${ }^{* * *}$ denote respectively statistical significance at the $10 \%, 5 \%$, and $1 \%$ levels.
(1)
$(2)$

VARIABLES Spread Eonia-DF Spread GC Eurex-DF Spread GC Eurex-Eonia

\begin{tabular}{|c|c|c|c|}
\hline \multirow[t]{2}{*}{ Lagged dependent variable } & $\begin{array}{c}-0.11^{* *} \\
{[0.05]}\end{array}$ & $\begin{array}{l}-0.06 \\
{[0.06]}\end{array}$ & $\begin{array}{c}-0.18^{* * *} \\
{[0.06]}\end{array}$ \\
\hline & 20.56 & 11.04 & 9.85 \\
\hline EURIBOR-OIS spread & {$[17.92]$} & {$[21.20]$} & {$[9.79]$} \\
\hline \multirow[t]{2}{*}{$\Delta$ Excess liquidity $[$ ConvMP] } & $-17.29 * * *$ & $-25.18^{* * *}$ & $6.41^{* * *}$ \\
\hline & {$[2.27]$} & {$[2.50]$} & {$[0.84]$} \\
\hline \multirow{2}{*}{$\Delta$ Excess liquidity [VLTRO] } & -0.52 & -1.50 & 1.04 \\
\hline & {$[0.68]$} & {$[1.22]$} & {$[0.70]$} \\
\hline \multirow[t]{2}{*}{ VLTRO } & -0.01 & 0.00 & 0.00 \\
\hline & {$[0.25]$} & {$[0.27]$} & {$[0.12]$} \\
\hline \multirow[t]{2}{*}{$\Delta$ Excess liquidity $[\mathrm{APP}]$} & -1.19 & $-3.39 * *$ & $2.53^{* * *}$ \\
\hline & {$[1.22]$} & {$[1.40]$} & {$[0.91]$} \\
\hline \multirow[t]{2}{*}{ APP } & -0.01 & 0.10 & -0.09 \\
\hline & {$[0.27]$} & {$[0.32]$} & {$[0.14]$} \\
\hline \multirow[t]{2}{*}{$\Delta$ Excess liquidity $[\mathrm{SFC}]$} & 2.41 & $5.68^{* * *}$ & $-3.68 * * *$ \\
\hline & {$[1.73]$} & {$[2.04]$} & [1.11] \\
\hline \multirow[t]{2}{*}{$\mathrm{SFC}$} & -0.08 & -0.15 & 0.08 \\
\hline & {$[0.29]$} & {$[0.32]$} & {$[0.09]$} \\
\hline \multirow[t]{2}{*}{$\mathrm{MRO}$} & -0.13 & -0.08 & -0.01 \\
\hline & {$[0.19]$} & {$[0.29]$} & {$[0.15]$} \\
\hline \multirow[t]{2}{*}{$\Delta \mathrm{VSTOXX}$} & -0.04 & -0.02 & 0.01 \\
\hline & {$[0.07]$} & {$[0.10]$} & {$[0.07]$} \\
\hline \multirow[t]{2}{*}{ End of maintenance period } & $5.49 * * *$ & $6.72^{* * *}$ & $-1.94 * * *$ \\
\hline & {$[1.29]$} & {$[1.46]$} & {$[0.60]$} \\
\hline \multirow[t]{2}{*}{ End of month } & $4.98^{* * *}$ & $6.80^{* * *}$ & $-1.93^{* * *}$ \\
\hline & {$[0.75]$} & {$[1.12]$} & [0.61] \\
\hline \multirow[t]{2}{*}{ End of quarter } & $16.13^{* * *}$ & $13.64^{* *}$ & 1.20 \\
\hline & {$[3.98]$} & {$[5.44]$} & {$[2.29]$} \\
\hline Observations & 2,251 & 2,274 & 2,251 \\
\hline
\end{tabular}




\subsection{Discussion of results}

Finally, in Table 2, we compare the results of our model with the main contributions from the literature, Poole (1968), Afonso and Lagos (2015) and Bech and Monnet (2016). We can see that our results on the effect of excess reserves and counterparty risk on the unsecured market are in line with the other studies. Namely, all the models show that interest rates decrease in excess reserves. Bech and Monnet (2016) and our model show that volumes decrease when excess reserves and counterparty risk increase as well as rates increase in counterparty risk. Afonso and Lagos (2015) and Bech and Monnet (2016) are the only ones to provide results regarding the cross-sectional volatility of interest rates thanks to their search and matching models.

We contribute to the literature but providing impacts of excess reserves and counterparty risk on the secured market. In particular, we show that excess reserves and counterparty risk have opposing effects on both rates and volumes: the former decreases both rates and volumes while the latter increases them. Moreover, unlike for the unsecured market, counterparty risk increases exchanged volumes on the secured market.

\begin{tabular}{|c|c|c|c|c|c|}
\hline \multirow{2}{*}{ Stylized facts } & \multirow{2}{*}{ Poole (1968) } & \multirow{2}{*}{ Afonso and Lagos (2015) } & \multirow{2}{*}{ Bech and Monnet (2016) } & \multicolumn{2}{|c|}{ Our model } \\
\hline & & & & Unsecured & Secured \\
\hline \multicolumn{6}{|c|}{ Excess reserves $\nearrow$} \\
\hline Rate & $\downarrow$ & $\downarrow$ & $\downarrow$ & $\downarrow$ & $\downarrow$ \\
\hline Rate volatility & na & $\downarrow$ & $\downarrow$ & na & na \\
\hline Total volume & $\rightarrow$ & $\rightarrow$ & $\downarrow$ & $\downarrow$ & $\downarrow$ \\
\hline \multicolumn{6}{|c|}{ Counterparty risk $\nearrow$} \\
\hline Rate & na & na & $\uparrow$ & $\uparrow$ & $\uparrow$ \\
\hline Total volume & na & na & $\downarrow$ & $\downarrow$ & $\uparrow$ \\
\hline
\end{tabular}

Table 2: Comparison with the literature

\section{Conclusion}

This paper documents several stylized facts on the interbank money markets: (i) banks are active on both markets even when their collateral constraint is not binding; (ii) volumes on both unsecured and repo markets drop when excess reserves raise; (iii) a surge in excess reserves drives the overnight rate on the unsecured market to the rate at which the central bank remunerates reserves and the overnight repo rate below this central bank rate.

We then build a model featuring both secured and unsecured interbank markets, in which competitive banks optimize their demand/supply in both markets. The model replicates the established stylized facts related to the functioning of these markets during conventional and unconventional monetary policies. We introduce two financial frictions to explain the aforementioned stylized facts: banks face (i) counterparty risk in the unsecured market and (ii) an opportunity cost to pledge collateral. 
Finally, we draw several predictions from the model with respect to how different monetary policies affect secured and unsecured interest rates. We define two monetary policies: the first one affects only liquidity supply whereas the second one alters both liquidity supply and marketable collateral base. The monetary policy altering solely excess reserves can be associated with VLTRO while the other one corresponds to the Eurosystem's Asset Purchasing Programme. We demonstrate empirically that in line with our model both monetary policy regimes affect unsecured interest rate in the same way; the secured interest rate relatively decreases when the central bank increases liquidity in the market by purchasing (reducing) marketable collateral; the spread between the secured and unsecured rates increases under monetary policy that purchases marketable collateral. However, due to the operational set-up, we are not able to confirm the hypothesis that the monetary policy solely increasing the liquidity supply decreases the spread because any monetary policy affects both liquidity supply and collateral base: even for conventional monetary policy operations (MRO, LTRO) the central bank provides loans against collateral thus altering the availability of the latter.

In line with ongoing debates on monetary policy implementation, two policy implications might be derived from our model. First, interbank markets are not perfect substitutes. Mechanisms underlying the interplay between unsecured and secured markets depend on the opportunity cost to pledge collateral. Second, conventional monetary policy (setting the corridor rates and reserve requirements) affects interest rates and volumes in the interbank markets, whereas unconventional monetary policy has also a twin effect on secured interest rates and on the composition between unsecured and secured markets through the supply of collateral. 


\section{References}

Afonso, Gara, and Ricardo Lagos, 2015, Trade dynamics in the market for federal funds, Econometrica 83, 263-313.

Amihud, Yakov, and Haim Mendelson, 1986, Asset pricing and the bid-ask spread, Journal of Financial Economics 17, 223-249.

Amstad, Marlene, and Antoine Martin, 2011, Monetary policy implementation: common goals but different practices, Current Issues in Economics and Finance 17.

Arciero, Luca, Ronald Heijmans, Richard Heuver, Marco Massarenti, Cristina Picillo, and Francesco Vacirca, 2016, How to measure the unsecured money market: The eurosystem's implementation and validation using target2 data, International Journal of Central Banking.

Arrata, William, Benoit Nguyen, Imene Rahmouni-Rousseau, and Miklos Vari, 2017, Eurosystem's asset purchases and money market rates, Banque de France Working Paper, No 652 .

Bech, Morten, and Elizabeth Klee, 2011, The mechanics of a graceful exit: Interest on reserves and segmentation in the federal funds market, Journal of Monetary Economics 58, 415-431.

Bech, Morten, and Cyril Monnet, 2013, The impact of unconventional monetary policy on the overnight interbank market, Liquidity and Funding Markets.

, 2016, A search-based model of the interbank money market and monetary policy implementation, Journal of Economic Theory 164, 32-67.

Bech, M. L., E. Klee, and V. Stebunovs, 2012, Arbitrage, liquidity and exit: The repo and federal funds markets before, during, and emerging from the financial crisis, Finance and Economics Discussion Series of Board of Governors of the Federal Reserve System (U.S.) 21.

Casassus, Jaime, and Pierre Collin-Dufresne, 2005, Stochastic convenience yield implied from commodity futures and interest rates, Journal of Finance 60, 2283-2331.

di Filippo, Mario, Angelo Ranaldo, and Jan Wrampelmeyer, 2016, Unsecured and secured funding, mimeo.

Duffie, Darrell, 1996, Specail repo rates, Journal of Finance 51, 493-526. 
Freixas, Xavier, and Cornelia Holthausen, 2005, Interbank market integration under asymmetric information, Review of Financial Studies 18, 459-490.

Furfine, C., 1999, The microstructure of the federal funds market, Financial Markets, Institutions, and Instruments 8, 24-44.

Gale, Douglas, and Tanju Yorulmazer, 2013, Liquidity hoarding, Theoretical Economics 8, 291-324.

Hauck, Achim, and Ulrike Neyer, 2014, A model of the eurosystem's operational framework and the euro overnight interbank market, European Journal of Political Economy 34, S65-S82.

Heider, F., and M. Hoerova, 2009, Interbank lending, credit-risk premia, and collateral, International Journal of Central Banking pp. 5-43.

Ho, Thomas S. Y., and Hans R. Stoll, 1983, The dynamics of dealer markets under competition, Journal of Finance 38, 1053-1074.

Huh, Yesol, and Sebastian Infante, 2017, Bond market intermediation and the role of repo, Finance and Economics Discussion Series 2017-003. Washington: Board of Governors of the Federal Reserve System.

Iori, Giulia, Giulia De Masi, Ovidiu Vasile Precup, Giampaolo Gabbi, and Guido Galdarelli, 2008, A network analysis of the italian overnight money market, Journal of Economic Dynamics 83 Control pp. 259-278.

Jackson, C., and M. Sim, 2013, Recent developments in sterling overnight money markets, Bank of England Quarterly Bulletin 53.

Jordan, Bradford D., and Susan D. Jordan, 1997, Special repo rates: An empirical analysis, Journal of Finance 52, 2051-2072.

Klee, E., and V. Stebunovs, 2013, Target practive: monetary policy implementation in a post-crisis environment, mimeo.

Krishnamurthy, Arvind, and Annette Vissing-Jorgensen, 2012, The aggregate demand for treasury debt, Journal of Political Economy 120, 233-267.

Mancini, Loriano, Angelo Ranaldo, and Jan Wrampelmeyer, 2016, The euro interbank repo market, The Review of Financial Studies 29, 1747-1779. 
Martin, A., J. McAndrews, A. Palida, and D. Skeie, 2013, Federal reserve tools for managing rates and reserves, Staff reports of Federal Reserve Bank of New York 642.

Poole, William, 1968, Commercial bank reserve management in a stochastic model: implications for monetary policy, Journal of Finance 23, 769-791.

Rainone, Edoardo, and Francesco Vacirca, 2016, Estimating the money market microstructure with negative and zero interest rates, Working paper of Banca d'Italia.

Ranaldo, Angelo, Matthias Rupprecht, and Jan Wrampelmeyer, 2016, Fragility of money markets, University of St. Gallen, School of Finance Research Paper No. 2016/01.

Vari, Miklos, 2016, Monetary policy transmission with interbank market fragmentation, mimeo.

Whitesell, William, 2006, Interest rate corridors and reserves, Journal of Monetary Economics 53, $1117-1195$. 


\section{Appendix}

\subsection{Institutional framework of European interbank markets}

We present the institutional framework of European interbank money markets and underlines features that play a crucial role in the model. European money markets encompass a wide variety of actors and instruments, for funding and other purposes. ${ }^{9}$ In our work, we focus on money markets designed for funding purposes and consider only European interbank markets, the unsecured and the Eurex GC Pooling markets.

The unsecured market is a benchmark to assess the transmission of monetary policy. The reference interest rate (Eonia) is calculated as the average rate at which banks in the panel lend to each other, and it traditionally follows the ECB main refinancing rate. The secured market has a more sophisticated structure, and we identify two main characteristics that distinguish it from the unsecured interbank one. First, it involves the exchange of liquidity and collateral, and both can motivate trade. The market is split into two segments: one is driven mostly by liquidity needs, GC Pooling, traded in CCP in our data sample, and the other mostly driven by a need of specific collateral, so called special trades, essentially done on a bilateral basis. This dichotomy is essential for the secured market. Second, the secured market is not purely interbank, financial institutions that seek secure investments and have cash take lending positions, whereas banks and other securities market intermediaries seek funding and dispose securities. Therefore, this market plays an important role in transmitting monetary policy to the wider financial market.

We seek to explain why rates could drop below the deposit facility rate in cash driven secured markets such as Eurex GC-pooling. Restricting the scope to the unsecured market and the GC market first allows us to avoid imperfect competition as there are only banks. Second, it stresses the role of the market infrastructure to transmit the opportunity cost to pledge collateral: re-use of collateral is limited to Eurex activities. Still, incentives to alleviate margin constraints for lenders stem from imperfect competition in the bond market or repo specialness. Therefore, our stylized framework of the money market includes the following key points:

- All agents are European banks: they are subject to reserve requirements and enjoy the same access to the central bank standing facilities,

- Banks trade reserves on two markets: unsecured and GC secured.

- Limited re-use of collateral inside the GC market prevents lenders to directly benefit from holding more bonds. Benefits are indirect: lending on the secured market alleviates their margin constraint and allows them to benefit from unpledged collateral.

\footnotetext{
${ }^{9}$ For more details on the aggregate statistics of these markets, refer to the Euro money market survey (2015) by the ECB and the European repo market survey (2017) from ICMA.
} 


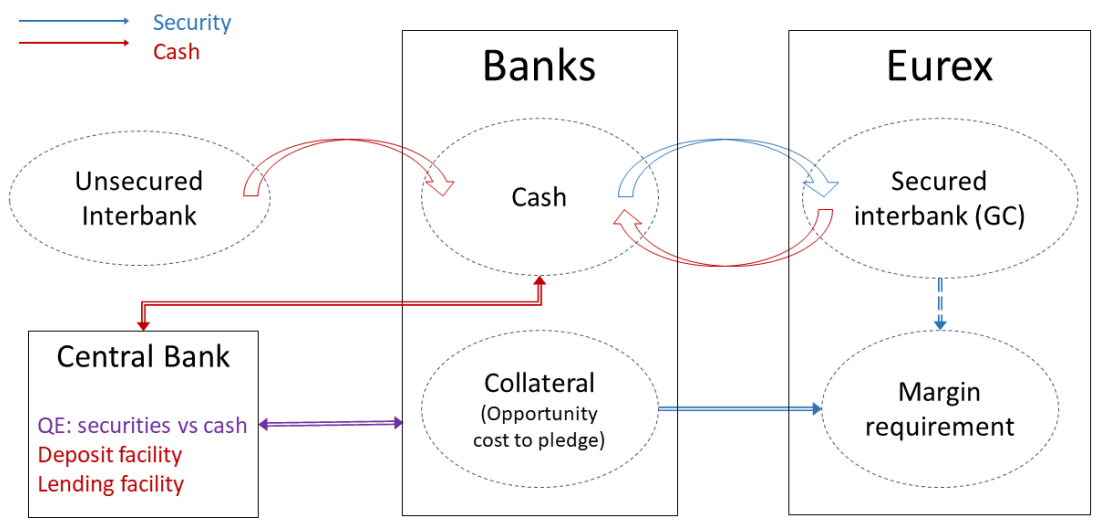

Figure 10: Institutional framework.

The figure presents the institutional framework we use in the paper. Banks trade reserves on both secured and unsecured money markets. They can access the central bank deposit and lending facilities. In addition, banks incur an opportunity cost to pledge collateral at their margin account with Eurex. They can substitute the collateral they need to pledge at their margin account with received collateral from the GC market.

In order to explain the limited re-use of collateral inside Eurex and provide details on how the GC market interacts with the rest of bond markets, it is worth highlighting some salient points about the GC Pooling market. This repo market is cash driven in the sense that collateral was initially settled to mitigate counterparty risk solely. Borrowers pledge collateral choosing among a basket of admissible securities. This basket is determined by Eurex. It consists of approximately 3000 ECB eligible marketable securities. ${ }^{10}$ Therefore, only highly liquid securities with limited counterparty risk are used as collateral inside the GC Pooling market. Furthermore, Eurex is the back office of "Deutsche Borse", where GC-market participants trade derivatives. They have to deposit collateral to fulfil initial margin requirements. Participants may fulfil their margin requirements ${ }^{11}$ using (i) bonds or stocks they choose to pledge among a basket of admissible securities, (ii) collateral received from the GC market, (iii) cash collateral. Hence, lenders in the GC market can substitute these three types of collaterals. Margin requirements transmit the opportunity cost to pledge bonds into GC rates: lenders may be willing to accept lower rates if collateral received allow them to reduce the quantity of bonds pledged.

Eurex collects fees on collateral used to fulfil margin requirements. ${ }^{12}$ We observe that cash and securities pledged as collateral entail fees collection whereas collateral received in the GC market does not incur any fee. Therefore, participants in the stock exchange have a clear incentive to become lender on Eurex GC market instead of paying their margins with cash. In addition, the Liquidity Coverage Ratio ${ }^{13}$ provides incentive to reduce cash margin. Indeed, cash margins are considered as unsecured loans to Eurex whereas lending in the GC market is considered as a secured loan. As a consequence, substituting cash with GC lending to fulfil margin requirements increases the "total cash inflows", thus increasing the LCR.

\footnotetext{
${ }^{10}$ More information on the list of eligible securities at EurexRepo, GCPoolingBaskets

${ }^{11}$ Collateral management is detailed here.

${ }^{12}$ Price list of Eurex Clearing is detailed here.

${ }^{13}$ Basel III: The Liquidity Coverage Ratio and liquidity risk monitoring tools.
} 


\subsection{Data sample}

To establish the stylized facts in section 2, we use two types of data on overnight funding, aggregate and individual. Stylized facts on the evolution of aggregate volumes in the interbank markets, SF2 (Figure 2), and of money market interest rates, SF3 (Figure 4), are shown using aggregate rates and volumes on unsecured funding (EONIA) and secured funding (Eurex GC Pooling). Data on EONIA rates and volumes are public. Eurex GC Pooling data are provided by Eurex at the transaction level and aggregated by us.

Regards the availability of collateral and substitution between secured and unsecured borrowing SF1 (Figure 1) and SF2 (Figure 3), we establish stylized facts at the individual bank level using transaction-level data from Eurex GC Pooling platform and TARGET2 payment system. For more details on the implementation and validation of the algorithm to filter out unsecured interbank loans in a large-value payment system TARGET2, we refer to Arciero, Heijmans, Heuver, Massarenti, Picillo, and Vacirca (2016). A potential problem of identifying interest rates when ECB main interest rate is zero or negative is discussed in Rainone and Vacirca (2016). The authors suggest that the standard approach by Furfine (1999) underestimates the frequency of unsecured loans when interest rates are zero, thus the period from June 2012 to June 2014. This aspect does not really affect our results due to two reasons: first, our analysis focuses on a larger period and mostly after 2014; second, applied corrections would change the frequency of observed loans but not the presence in aggregate of substitution between unsecured and secured funding.

Information on collateral pledged at the Eurosystem comes from TARGET2 credit lines. The latter constitutes a buffer of collateral available for daily shortages of liquidity to make payments and for monetary policy operations. Collateral consists of marketable and non-marketable securities; however, up to $80 \%$ are marketable securities for banks in our sample. TARGET2 started its operation in 2008 with gradient transition. Until end-2013, banks in several national banking systems were allowed to use previous solutions to manage their liquidity without passing by credit lines. Therefore, reliable data on credit lines start only from 2014.

Our sample consists of 52 banks of a different size and market activity. We start by selecting banks active on the secured market and then match them with funding volumes on the unsecured market. These banks represent on average about $60 \%$ of total volume of the GC Pooling market and about $30 \%$ of the unsecured market.

\subsection{Demands and supply of funding}

\section{DEMAND FOR UNSECURED FUNDING}

Consider the quantities on the secured market as given. The demand for unsecured funding solves the first F.O.C along with the complementary condition: 


$$
\begin{aligned}
& -r_{u}+r_{d}+\left(r_{p}-r_{d}\right) F(-m+\nu-q)+\lambda_{u, B}=0 \\
& \lambda_{u, B} q_{u}=0
\end{aligned}
$$

Thus, the demand for unsecured funding is null if the unsecured rate is above $r_{u, B}$. If the demand is positive, then $\lambda_{u, B}=0$ and $q_{u}$ is such that the marginal profit is null. Note $D_{u}\left(q_{s}, r\right)$ the demand for unsecured borrowing. It writes

$$
D_{u}\left(q_{s}, r\right)= \begin{cases}0 & \text { if } r_{u}>r_{u, B}\left(q_{s}\right) \\ q_{u} & \text { such that } r_{u}=r_{d}+\left(r_{p}-r_{d}\right) F(-m+\nu-q) \text { otherwise }\end{cases}
$$

\section{DEMAND FOR SECURED FUNDING}

Conversely, consider the quantities on the unsecured market as given. The demand for secured borrowing solves the following system:

$$
\begin{aligned}
& -r_{s}-K^{\prime}\left(b_{0}-q_{s}\right)+r_{d}+\left(r_{p}-r_{d}\right) F(-m+\nu-q)-\mu_{B}+\lambda_{s, B}=0 \\
& \mu_{B}\left(b_{0}-q_{s}\right)=0 \\
& \lambda_{s, B} q_{s}=0
\end{aligned}
$$

Likewise, the demand is:

$$
D_{s}\left(q_{u}, r\right)= \begin{cases}0 & \text { if } r_{s}>\bar{r}_{s, B}\left(q_{u}\right) \\ q_{s} & \text { st } r_{s}+K^{\prime}\left(b_{0}-q_{s}\right)=r_{d}+\left(r_{p}-r_{d}\right) F(-m+\nu-q) \text { if } r_{s} \in\left[\underline{r}_{s, B}\left(q_{u}\right), \bar{r}_{s, B}\left(q_{u}\right)\right] \\ b_{0} & \text { if } r_{s}<\underline{r}_{s, B}\left(q_{u}\right)\end{cases}
$$

\section{SUPPLY OF UNSECURED FUNDING}

Consider the quantities on the secured market as given. The supply of unsecured funding solves the first F.O.C along with the complementary condition:

$$
\begin{aligned}
& -p r_{u}+(1-p)+r_{d}+\left(r_{p}-r_{d}\right) F(-m-\nu+q)-\lambda_{u, L}=0 \\
& \lambda_{u, L} q_{u}=0
\end{aligned}
$$

Thus, the supply of unsecured funding is null if the unsecured rate is below $r_{u, L}$. If the demand is positive, then $\lambda_{u, L}=0$ and $q_{u}$ is such that the marginal profit is null. Note $S_{u}\left(q_{s}, r\right)$ the supply of unsecured funding. It writes 


$$
S_{u}\left(q_{s}, r\right)= \begin{cases}0 & \text { if } r_{u}<r_{u, L}\left(q_{s}\right) \\ q_{u} & \text { such that } p r_{u}=1-p+r_{d}+\left(r_{p}-r_{d}\right) F(-m-\nu+q) \text { otherwise }\end{cases}
$$

\section{SUPPLY OF SECURED LENDING}

Consider the quantities on the secured market as given. The supply of secured funding solves the first F.O.C along with the complementary condition:

$$
\begin{aligned}
& -r_{s}-K^{\prime}\left(b_{0}+q_{s}\right)+r_{d}+\left(r_{p}-r_{d}\right) F(-m-\nu+q)-\lambda_{s, L}=0 \\
& \lambda_{s, L} q_{s}=0
\end{aligned}
$$

Thus, the supply of secured funding is null if the secured rate is below $r_{s, L}$. If the demand is positive, then $\lambda_{s, L}=0$ and $q_{s}$ is such that the marginal profit is null. Note $S_{s}\left(q_{u}, r\right)$ the supply of unsecured funding. It writes

$$
S_{s}\left(q_{s}, r\right)= \begin{cases}0 & \text { if } r_{s}<r_{s, L}\left(q_{u}\right) \\ q_{s} & \text { such that } r_{s}+K^{\prime}\left(b_{0}+q_{s}\right)=r_{d}+\left(r_{p}-r_{d}\right) F(-m-\nu+q) \text { otherwise }\end{cases}
$$

\subsection{Proof of Lemma 3.2}

Assume $q \geq \nu$. We use the market clearing conditions and differentiate two cases.

Case (a): the unsecured market is active, $q_{u}>0$. Market clearing condition implies

$$
r_{d}+\left(r_{p}-r_{d}\right) F(-m+\nu-q)=\frac{1}{p}\left(1-p+r_{d}+\left(r_{p}-r_{d}\right) F(-m-\nu+q)\right) .
$$

$q \geq \nu$ implies that $F(-m+\nu-q) \leq F(-m-\nu+q)$. It violates the market clearing condition as $p<1$.

Case (b): the secured market is active, $q_{s}>0$. Market clearing condition writes:

$$
-K^{\prime}\left(b_{0}-q_{s}\right)+\left(r_{p}-r-d\right) F(-m+\nu-q)=-K^{\prime}\left(b_{0}+q_{s}\right)+\left(r_{p}-r-d\right) F(-m+\nu-q) .
$$

$F(-m+\nu-q) \leq F(-m-\nu+q)$ along with $K^{\prime}\left(b_{0}-q_{s}\right)>K^{\prime}\left(b_{0}+q_{s}\right)$ violates the market clearing condition.

The argument holds if the two markets are active.

Hence, $q<\nu$. 


\subsection{Interbank equilibria}

Lemma 6.1 (Interbank equilibria). If $p<1$, we may have different equilibria depending on parameters values:

1. $q_{u}=0, q_{s}<b_{0}$ :

$$
\left\{\begin{array}{l}
r_{d}+\left(r_{p}-r_{d}\right) F\left(-m+\nu-q_{s}\right) \leq \frac{1}{p}\left(1-p+r_{d}+\left(r_{p}-r_{d}\right) F\left(-m-\nu+q_{s}\right)\right) \\
\left(r_{p}-r_{d}\right)\left(F\left(-m+\nu-q_{s}\right)-F\left(-m-\nu+q_{s}\right)\right)=K^{\prime}\left(b_{0}-q_{s}\right)-K^{\prime}\left(b_{0}+q_{s}\right)
\end{array}\right.
$$

2. $q_{u}=0, q_{s}=b_{0}$ :

$$
\left\{\begin{array}{l}
r_{d}+\left(r_{p}-r_{d}\right) F\left(-m+\nu-b_{0}\right) \leq \frac{1}{p}\left(1-p+r_{d}+\left(r_{p}-r_{d}\right) F\left(-m-\nu+b_{0}\right)\right) \\
\left(r_{p}-r_{d}\right)\left(F\left(-m+\nu-b_{0}\right)-F\left(-m-\nu+b_{0}\right)\right) \geq K^{\prime}(0)-K^{\prime}\left(2 b_{0}\right)
\end{array}\right.
$$

3. $q_{u}>0, q_{s}<b_{0}$ :

$$
\left\{\begin{array}{l}
r_{d}+\left(r_{p}-r_{d}\right) F(-m+\nu-q)=\frac{1}{p}\left(1-p+r_{d}+\left(r_{p}-r_{d}\right) F(-m-\nu+q)\right) \\
\left(r_{p}-r_{d}\right)(F(-m+\nu-q)-F(-m-\nu+q))=K^{\prime}\left(b_{0}-q_{s}\right)-K^{\prime}\left(b_{0}+q_{s}\right)
\end{array}\right.
$$

4. $q_{u}>0, q_{s}=b_{0}$ :

$$
\left\{\begin{array}{l}
r_{d}+\left(r_{p}-r_{d}\right) F\left(-m+\nu-q_{u}-b_{0}\right)=\frac{1}{p}\left(1-p+r_{d}+\left(r_{p}-r_{d}\right) F\left(-m-\nu+q_{u}+b_{0}\right)\right) \\
\left(r_{p}-r_{d}\right)\left(F\left(-m+\nu-q_{u}-b_{0}\right)-F\left(-m-\nu+q_{u}+b_{0}\right)\right) \geq K^{\prime}(0)-K^{\prime}\left(2 b_{0}\right)
\end{array}\right.
$$

\subsection{Proof of theorem 3.2}

Remember banks are active on both market, with $q_{u}>0$ and $q_{s} \in\left(0, b_{0}\right)$. We prove the excess demand for unsecured funding increases with $r_{s}$. We proceed in steps.

First, $\frac{\partial D_{s}}{\partial r_{s}}<0$. It implies, that $\frac{\partial D_{u}\left(D_{s}=q_{s}\right)}{\partial r_{s}}>0$.

Second, $\frac{\partial S_{s}}{\partial r_{s}}>0$. It implies, that $\frac{\partial S_{u}\left(S_{s}=q_{s}\right)}{\partial r_{s}}<0$.

Note, $Z_{u}=D_{u}-S_{u}$, the inequalities above imply

$$
\frac{\partial Z_{u}}{\partial r_{s}}>0
$$

We proceed in a similar way to prove

$$
\frac{\partial Z_{s}}{\partial r_{u}}>0
$$

\subsection{Proof of proposition 4.1}

We first prove $\underline{p}<\bar{p}$. 
$\underline{p}$ is the boundary such that $q_{u}(p \leq \underline{p})=0$, i.e.

$$
\underline{p}=\frac{1+r_{d}+\left(r_{p}-r_{d}\right) F(-m-\nu+\underline{q})}{1+r_{d}+\left(r_{p}-r_{d}\right) F(-m+\nu-\underline{q})}
$$

with, $\underline{q}=q_{s}$.

$\bar{p}$ is the boundary such that $q_{s}(p \leq \bar{p})=b_{0}$,

$$
\bar{p}=\frac{1+r_{d}+\left(r_{p}-r_{d}\right) F(-m-\nu+\bar{q})}{1+r_{d}+\left(r_{p}-r_{d}\right) F(-m+\nu-\bar{q})}
$$

with $\bar{q}=b_{0}+q_{u}$. Notice first that $\bar{q}>\underline{q}$. Hence,

$$
\underline{p}<\bar{p} \Leftrightarrow \frac{F(-m-\nu+\underline{q})}{F(-m+\nu-\underline{q})}<\frac{F(-m-\nu+\bar{q})}{F(-m+\nu-\bar{q})}
$$

$\bar{q}>\underline{q}$ implies that $F(-m+\nu-\underline{q})>F(-m+\nu-\bar{q})$ and $F(-m-\nu+\underline{q})<F(-m-\nu+\bar{q})$. Therefore,

$$
\frac{F(-m-\nu+\underline{q})}{F(-m+\nu-\underline{q})}<\frac{F(-m-\nu+\underline{q})}{F(-m+\nu-\bar{q})}<\frac{F(-m-\nu+\bar{q})}{F(-m+\nu-\bar{q})}
$$

which ensures $\underline{p}<\bar{p}$.

1. If $p=1$, then banks perfectly insure their payment shocks $(q=\nu) \cdot K^{\prime}\left(b_{0}-q_{s}\right)-K^{\prime}\left(b_{0}+q_{s}\right)=$ $0 \Rightarrow q_{s}=0$.

2. If $p \in(\bar{p}, 1)$, then the solution lies in the system (6.25).

3. If $p \in(\underline{p}, \bar{p}]$, then the solution lies in (6.26).

4. If $p \geq p$, then the solution lies in (6.24)

If $\left(r_{p}-r_{d}\right)\left(F\left(-m+\nu-b_{0}\right)-F\left(-m-\nu+b_{0}\right)\right)<K^{\prime}(0)-K^{\prime}\left(2 b_{0}\right)$, then $q_{s}<b_{0}$. It implies, the solution lies in (6.25) for $p>\hat{p}$ and in (6.23) for $p \leq \hat{p}$.

Comparative statics: effect of $p$ on $q_{u}$ and $q_{s} \quad$ Case 1 and 2: $q_{u}=0$. Then $\frac{\partial q_{u}}{\partial p}=0$, and $\frac{\partial q_{s}}{\partial p}=$ 0 .

Case 4: $q_{u}>0$ and $q_{s}=b_{0}$. We have $\frac{\partial q_{s}}{\partial p}=0$. As for $\frac{\partial q_{u}}{\partial p}$, differentiating the market clearing condition with respect to $p$ yields

$$
\frac{\partial q_{u}}{\partial p}=\frac{1+\left(r_{p}-r_{d}\right) F(-m+\nu-q)}{\left(r_{p}-r_{d}\right)(f(-m-\nu+q)+p f(-m+\nu-q))} .
$$

Case 3: $q_{u}>0$ and $q_{s}<b_{0}$. Differentiating market clearing conditions yields 


$$
\left\{\begin{array}{l}
\left(r_{p}-r_{d}\right) F(-m+\nu-q)-q^{\prime} p\left(r_{p}-r_{d}\right) f(-m+\nu-q)=-1+q^{\prime}\left(r_{p}-r_{d}\right) f(-m-\nu+q) \\
q^{\prime}\left(r_{p}-r_{d}\right)(f(-m+\nu-q)+f(-m-\nu+q))=q_{s}^{\prime}\left(K^{\prime \prime}\left(b_{0}-q_{s}\right)+K^{\prime \prime}\left(b_{0}+q_{s}\right)\right)
\end{array}\right.
$$

which gives

$$
\left\{\begin{array}{l}
q^{\prime}=\frac{1+\left(r_{p}-r_{d}\right) F(-m+\nu-q)}{\left(r_{p}-r_{d}\right)(f(-m-\nu+q)+p f(-m+\nu-q))} \\
q_{s}^{\prime}=\frac{q^{\prime}\left(r_{p}-r_{d}\right)(f(-m+\nu-q)+f(-m-\nu+q))}{K^{\prime \prime}\left(b_{0}-q_{s}\right)+K^{\prime \prime}\left(b_{0}+q_{s}\right)}
\end{array}\right.
$$

Hence, $q^{\prime}>0$ and $q_{s}^{\prime}<0$, which implies $q_{u}^{\prime}>0$.

\subsection{Proof of proposition 4.2}

We first prove $\bar{m}>\underline{m}$. The market clearing condition in the unsecured market yields

$$
\left(r_{p}-r_{d}\right)(p F(-m+\nu-q)-F(-m-\nu+q))=\frac{(1-p)\left(1+r_{d}\right)}{r_{p}-r_{d}} .
$$

By assumption, $q(\underline{m})>q(\bar{m})$, the above equality implies $\bar{m}>\underline{m}$.

\section{Impact of $m$ on quantities exchanged:}

Case (a): no trade in the unsecured market.

If $q_{s}=b_{0}$, then $\frac{\partial q_{s}}{\partial b_{0}}=0$. Instead, if $q_{s}<b_{0}$, we have

$$
\begin{array}{r}
\left(r_{p}-r_{d}\right)\left(\left(-1-q_{s}^{\prime}\right) f\left(-m+\nu-q_{s}\right)-\left(-1+q_{s}^{\prime}\right) f\left(-m-\nu+q_{s}\right)\right)= \\
-q_{s}^{\prime}\left(K^{\prime \prime}\left(b_{0}-q_{s}\right)+K^{\prime \prime}\left(b_{0}+q_{s}\right)\right) .
\end{array}
$$

It follows

$$
q_{s}^{\prime}=\frac{-K^{\prime \prime}\left(b_{0}-q_{s}\right)-K^{\prime \prime}\left(b_{0}+q_{s}\right)+\left(r_{p}-r_{d}\right)\left(f\left(-m+\nu-q_{s}\right)+f\left(-m-\nu+q_{s}\right)\right.}{\left(r_{p}-r_{d}\right)(f(-m-\nu+q)-f(-m+\nu-q))} .
$$

The numerator is positive. $m>0$ and imperfect insurance $\nu-q>0$ imply that

$$
-m-\nu+q<-m+\nu-q .
$$

It follows

$$
f(-m-\nu+q)<f(-m+\nu-q) .
$$


Therefore, we have $\frac{\partial q_{s}}{\partial m} \leq 0$ if $q_{u}=0$.

Case (b): trade in both markets.

If $q_{s}=b_{0}$, then $\frac{\partial q_{s}}{\partial b_{0}}=0$. The analogue calculation than in case (a) can be undertaken to prove $\frac{\partial q_{u}}{\partial b_{0}} \leq 0$ in this case. Now assume $q_{u}>0$ and $q_{s}<b_{0}$, the differentiation is more tedious as the two quantities move simultaneously. Differentiating the system (6.25) yields:

$$
\left\{\begin{array}{l}
q^{\prime}=\frac{f(-m-\nu+q)-p f(-m+\nu-q)}{f(-m-\nu+q)+p f(-m+\nu-q)} \\
\left(r_{p}-r_{d}\right)\left(\left(-1-q^{\prime}\right) f\left(-m+\nu-q_{s}\right)-\left(-1+q^{\prime}\right) f\left(-m-\nu+q_{s}\right)\right)=-q_{s}^{\prime}\left(K^{\prime \prime}\left(b_{0}-q_{s}\right)+K^{\prime \prime}\left(b_{0}+q_{s}\right)\right)
\end{array}\right.
$$

with $q^{\prime}=q_{s}^{\prime}+q_{u}^{\prime}$. Lets determine the sign of $f(-m-\nu+q)-p f(-m+\nu-q)$. Using the market clearing condition in the unsecured market, the sign of $f(-m-\nu+q)-p f(-m+\nu-q)$ is the same than the one of

$$
\begin{array}{r}
\left(1+r_{d}\right)(f(-m-\nu+q)-f(-m+\nu-q))+ \\
\left(r_{p}-r_{d}\right)(f(-m-\nu+q) F(-m+\nu-q)-f(-m+\nu-q) F(-m+\nu-q))
\end{array}
$$

The first term is negative, and $r_{p}-r_{d} \ll 1$ implies $\frac{\partial q}{\partial m}<0$.

The second equation yields

$$
q_{s}^{\prime}=\frac{r_{p}-r_{d}}{K^{\prime \prime}\left(b_{0}-q_{s}\right)+K^{\prime \prime}\left(b_{0}+q_{s}\right)} \frac{2 f(-m-\nu+q) f(-m+\nu-q)(1-p)}{f(-m-\nu+q)+p f(-m+\nu-q)} .
$$

Eventually, $\frac{\partial q_{s}}{\partial m}<0$.

$$
q_{u}^{\prime}=\frac{f(-m-\nu+q)-p f(-m+\nu-q)-\frac{r_{p}-r_{d}}{K^{\prime \prime}\left(b_{0}-q_{s}\right)+K^{\prime \prime}\left(b_{0}+q_{s}\right)} 2 f(-m-\nu+q) f(-m+\nu-q)(1-p)}{f(-m-\nu+q)+p f(-m+\nu-q)} .
$$

Using the market clearing condition in both markets, we have:

$$
\begin{array}{r}
q_{u}^{\prime}<\frac{1}{\left(f_{1}+p f_{2}\right)\left(1+r_{d}+\left(r_{p}-r_{d}\right) F_{2}\right.} \\
\left(\left(1+r_{d}\right)\left(f_{1}-f_{2}\right)+\left(r_{p}-r_{d}\right)\left(f_{1} F_{2}-f_{2} F_{1}+2 f_{1} f_{2} \frac{K^{\prime}\left(b_{0}-q_{s}\right)-K^{\prime}\left(b_{0}+q_{s}\right)}{K^{\prime \prime}\left(b_{0}-q_{s}\right)+K^{\prime \prime}\left(b_{0}+q_{s}\right)}\right)\right)
\end{array}
$$

with $f_{1}=f(-m-\nu+q), f_{2}=f(-m+\nu-q), F_{1}=F(-m-\nu+q)$, and $F_{2}=F(-m+\nu-q)$. A 
sufficient condition for $q_{u}^{\prime}<0$ is

$$
\left(r_{p}-r_{d}\right) 2 f_{1} \frac{K^{\prime}\left(b_{0}-q_{s}\right)-K^{\prime}\left(b_{0}+q_{s}\right)}{K^{\prime \prime}\left(b_{0}-q_{s}\right)+K^{\prime \prime}\left(b_{0}+q_{s}\right)} \ll 1
$$

Assume this is not the case. Note $K_{\text {min }}^{\prime \prime}=\min \left(K^{\prime \prime}\left(b_{0}-q_{s}\right), K^{\prime \prime}\left(b_{0}+q_{s}\right)\right)$ and $K_{\max }^{\prime \prime}=\max \left(K^{\prime \prime}\left(b_{0}-\right.\right.$ $\left.\left.q_{s}\right), K^{\prime \prime}\left(b_{0}+q_{s}\right)\right)$. By definition,

$$
K^{\prime}\left(b_{0}-q_{s}\right)-K^{\prime}\left(b_{0}+q_{s}\right) \in\left[-K_{\min }^{\prime \prime} 2 q_{s},-K_{\max }^{\prime \prime} 2 q_{s}\right] .
$$

We also have

$$
\left|\frac{K^{\prime}\left(b_{0}-q_{s}\right)-K^{\prime}\left(b_{0}+q_{s}\right)}{K^{\prime \prime}\left(b_{0}-q_{s}\right)+K^{\prime \prime}\left(b_{0}+q_{s}\right)}\right| \sim \frac{1}{2 f_{1}\left(r_{p}-r_{d}\right)}
$$

Thus,

$$
\left|K^{\prime}\left(b_{0}-q_{s}\right)-K^{\prime}\left(b_{0}+q_{s}\right)\right| \sim \frac{K^{\prime \prime}\left(b_{0}-q_{s}\right)+K^{\prime \prime}\left(b_{0}+q_{s}\right)}{2} \frac{1}{f_{1}\left(r_{p}-r_{d}\right)},
$$

which ends up in a contradiction as $\frac{1}{f_{1}\left(r_{p}-r_{d}\right)}$ is large compared to $2 q_{s}$. 